\title{
4 Points of redefinition: distribution, firing lists, and kiln loads (1st century AD)
}

At the end of the previous chapter terra sigillata was produced, the pots had been made. But it was not 'just' produced, it was produced in a particular way: as a category. Its production practices lined up to define sigillata as a bounded thing, clearly separate from other production sequences, and identifiable through a package of traits. The logical next step is distribution, the trading of sigillata pots. But practices of distribution posed rather different requirements for sigillata than production. Work was needed to assure a smooth transition from the pots' definition in production to their role in distribution. How was sigillata made into a trade-able, calculable object? How did its definition as a category facilitate this?

The so-called firing lists provide a unique transcript of sigillata pots' definition at exactly this crucial turning point between production and distribution. Incorporating these lists requires the narrative of this book to rewind by a century to the 1st century $\mathrm{AD}$ and to move from the production site of Lezoux to that of La Graufesenque in South Gaul (Fig. 3.2). Although a full empirical description exceeds the scope of this work, recent data underwrite the likelihood that a process comparable to the category emergence described in the previous chapter for Lezoux unfolded at La Graufesenque a century earlier. ${ }^{351}$ This chapter's chronological and geographical switch to pots produced at La Graufesenque therefore does not invalidate the overall historical trajectory of sigillata-as-a-category. Once sigillata left the production site, a series of intermediate stages again posed different requirements for sigillata. A collection of assemblages of unused South Gaulish sigillata dated to the 1st century AD at crucial points of turnover enable a continued description of the category's trajectory. Moreover, these assemblages provide an arena to demonstrate how consideration of sigillata's role as history-maker changes its use as history-teller, in this case its use as evidence for trade mechanisms.

\section{I TRAJECTORIES AND REDEFINITION IN ECONOMIC NARRATIVES}

Attention to the redefinition of things along their trajectories of exchange is far from new. In economic anthropology, such redefinition came into the picture with substantivism. ${ }^{352}$ In opposition to formalism, which posited rational, maximizing market behaviour as a universal template for economic action, substantivism situated this behaviour within a specific set of social and historical relations (embeddedness ${ }^{353}$ ), as channelled through institutions (institutedness; e.g. legal contracts). It follows that different historical and institutional settings give rise to different kinds of economic action and exchange. Thinking this through to the 'things' characterized by different kinds of exchange relations, economic anthropologists differentiated between gifts and commodities. The gift is characterized as a personalized form of exchange, embedded in social ties from which it is inalienable; while the commodity is seen as a utilitarian form of exchange, disembedded from wider social or cultural ties. ${ }^{354}$

\footnotetext{
351 But at La Graufesenque, the choice of clay (which had always been calcareous) did not play a pivotal role, in contrast to Lezoux.

352 E.g. Munn 1986. Studies by Mauss, Weiner, Gregory,
}

354 Miller 2000. 
Gifts and commodities come with different consequences for action. Think for instance about how one normally removes the price tag from a wine bottle one brings as a gift to a dinner party, because price is not seen as contributing to its value in that setting, which is thought to reside more in 'immaterial' considerations such as friendship, thoughtfulness, etc. Without a price tag, however, it would have been impossible to buy that same bottle in the supermarket, as a commodity. But not only does this distinction not map onto modern versus ancient economies (gift-giving is still around in today's market economy), the boundary between both types is often blurred (gift-giving often implies calculation, and commodity exchange does not preclude emotional attachment and judgment). ${ }^{355}$

An attempt at taking up the notion of institutedness within a neoclassical economic framework is New Institutional Economics (NIE). ${ }^{356}$ NIE tries to curb the neoclassical model of frictionless and predictable rational action by modelling how all economic action is channelled through formal (law, firms, demography, technology, etc.) and informal (norms, customs, beliefs, etc.) institutions. But both NIE and its recent offshoots in Roman studies (with the Cambridge Economic History of The Greco-Roman World as a landmark) are hampered by the sharp distinction they maintain between 'formal' and 'informal' institutions. ${ }^{357}$ Demography, for example, is about ('formal') biological conditions as much as about ('informal') social norms (e.g. birth control), and from the preceding chapter it should be clear that technology is not simply restricted by natural laws but embodied, experienced, and learnt.

Substantivist studies of gifts and commodities, and NIE are two attempts at relating economic forms to social and historical structures. In theory, then, they can accommodate redefinitions of things: as the social and historical structures of exchange alter, so do the parameters for the things exchanged. But this potential remains largely untapped because the building block of these analyses as well as the agent of change remains the individual human actor. ${ }^{358}$ Things are again approached retrospectively, as chosen, rejected, given meaning, or desired by human agents; as history-tellers, not history-makers.

A non-retrospective approach to things in economic transactions requires emphasizing the material practices of exchange, just like the previous chapters did for the practices of study and production. This non-retrospective move has been made in recent studies of the modern market system (in particular by M. Callon), which look at practices to decide what is seen as constitutive of a certain actor or thing, what was taken into account in a transaction and what not. ${ }^{359}$ For example, the purchase of a bottle of wine in the supermarket hinges on the alignment of calculation devices, re-shelving, cashiers, trucks, but also regional drinking customs, social age restrictions, ID cards and so on. This network of practices stabilizes the bottle of wine as a transactable thing defined by a package of traits including price (in a standard currency), contents (one of a limited series of possible modules), percentage of alcohol contents, etc. Certain actors are taken into account, while others are excluded. But this does not run along the divide between formal and informal institutions: the lorries driving up and down along highways and back alleys that have to be wide enough can have the same input in the analysis as the socially sanctioned practice of alcohol consumption. The bottle of wine as transactable thing in the supermarket is kept separate from the environmental taxes for lorries transporting the wine bottles, and from debates on whether or not alcohol qualifies as a soft drug. ${ }^{360}$ But this separation is constantly challenged. If the

355 Miller 2000, building on Bourdieu 1979 and Appadurai 1986.

356 North 1990; Williamson 2000. Critique by Boldizzoni 2011; positive review by Bang 2009.

357 Cf. a modernist dichotomy between nature and culture (Latour 1993). In later work North (2005) tries to take on board more complex models of human/world interaction (e.g. Clark 2008 on cognitive psychology), but fails to articulate the consequences for the institutional framework.
358 Barry/Slater 2002, 184; e.g. North 1990, 48, 83 and passim; Greene 2005, 2006 for a similar critique from a more traditional perspective

359 Callon 1999. Santos/Rodrigues 2009 for a critique based on the disciplinary practices of economics. Miller 2002a argues that such 'framing' that keeps certain considerations out of economic transactions does not exist in reality. But see Callon 2005; Callon/Latour 2011.

360 'Externalities': Callon 1998b; Callon/Latour 2011. 
supermarket personnel fail to maintain a strict policy of ID verification, this might result in increased alcohol consumption among those below the legal age limit, and, as a consequence, this legal frame might be adjusted. ${ }^{361}$ Or, the other way round, if the environment becomes a matter of concern that is institutionalized in increased taxes for motor traffic, this will affect the supermarket's supplies and might lead to new sales strategies.

As a transactable item on the supermarket shelves, then, the wine bottle is characterised by a limited and standardized package of traits, and by a clear but actively maintained boundary with other products and debates. This strikes a parallel with sigillata's definition as a category in production practices at 2nd century Lezoux, discussed in the previous chapter. This chapter will examine whether this definition similarly made sigillata into a transactable thing, shaping its trajectory of exchange in a particular way. It will also ask how this definition was maintained.

The questions of maintenance and stability are new and important: changes to material practices that previously seemed trivial (e.g. transport by train instead of lorry; introduction of a new volume module for wine bottles), can now shuffle an entire network of meaning and power. ${ }^{362}$ Firstly, depending on how economic action is channelled, the semantic position of a bottle of wine changes: it is drawn closer to narratives of the environment, contrasted with a rhetoric of youth education, or distanced from a French blueprint of conviviality. Secondly, the very kind of thing that a bottle of wine is - the way it is understood and grasped - alters too. From a unit defined by a certain volume and several vintages that are reducible to price differences in the store (a category), to a more fuzzily grasped source of pleasure ('it tastes good'), the right accompaniment to a specific dish ('fish should go with white wine'), or a quick medium for getting drunk ('13\% alcohol'). ${ }^{363}$ Whether it is wine or sigillata, material culture is not always and self-evidently defined as a category, in contrast to the assumption of retrospective accounts. This sparks new questions, such as how the purchase of a bottle of wine in the supermarket is made possible; or why certain things can be compared based on price and brand, while this is impossible or "not done' for others; or how one knows to bring a bottle of wine and not a stapler as a gift to a dinner party.

An example from Roman studies is the legal enforcement of liability for sellers of slaves who had to notify potential customers about diseases and other 'defaults'. ${ }^{364}$ This illustrates a specific instance of negotiation between different definitions of the slave: by the buyer who wants a good price, and by the seller who is looking for a reliable member of the household. Institutions such as legal arrangements and social norms about disease channelled these negotiations in a particular way. The resulting setting in turn defined the slave in a specific way - as either 'healthy' or 'not healthy' - to the detriment of many other possible definitions, based on other parameters, such as origin, skills, age, etc. One could for instance envisage a skill-based definition of the slave along much more fluid lines than allowed for by a binary qualifier: skills could overlap (and/and), be nested (skill a implies skill b), be present to various degrees (skill a and a bit of skill b), etc.

How then was sigillata made into a trade-able object? And how did this relate to its definition as a category through production practices?

\footnotetext{
361 'Overflows': the effects of action in a certain setting on actors not taken into account in that setting (Callon/Law 2005, 722; Callon 1998b).

362 Slater/Tonkiss 2001, 116; Slater 2002c, 247.

363 Callon/Law 2005 on 'qualculation'. That 'unquantifiable'
}

experiences are often framed by carefully arranged practices is illustrated by Gomart/Hennion 1999 on drugs and music.

364 Frier/Kehoe 2007, 120. 


\subsection{FIRING LISTS: PIN ING D OW N A PACKAGE OF TRAITS}

4.2. I S TATE OF RESEARCH

Found at the production site of La Graufesenque in South Gaul (near present-day Millau, Fig. 3.2), the firing lists are key documents in sigillata studies ${ }^{365}$ The lists were inscribed on actual sigillata plates after they were slipped but before firing. In separate columns they describe names, vessel types, dimensions and quantities (Figs. 4.1 and 4.2). A formalized heading precedes the tallies, and at the end the sum total is made of the quantities listed. The majority of the lists are dated to the Neronian and Flavian periods (second half of the 1st century AD), based on the attested potters' names and on the typology of the plates. ${ }^{366}$ Similar Roman 'tally lists' inscribed on tiles before firing are found on various Gaulish sites engaged in tile production. Some of those graffiti ante cocturam on tiles date a series of quantities linked to a series of potters, while making the sum at the end. ${ }^{367}$ These lists are however a much more dispersed phenomenon than the concentration of firing lists found at La Graufesenque, and they lack the formulaic character of the sigillata tallies. The dates in their heading, for instance, do not refer to a local standard as with the sigillata firing lists (the number of firing events in a season) but to the Roman calendar system (e.g. Kalendis Iulis). This suggests that even if the use of simple tallies was not unique to sigillata production, the firing lists were doing something more specific to sigillata, and to its production context.

The accepted estimate of pots produced at, and exported from, La Graufesenque in this period amounts to 15 million per year. ${ }^{368}$ These figures alone postulate organisational strategies for coping with this massive flow of goods, and the lists fit remarkably well in this frame as accounting devices avant la lettre. Hence they are taken to provide a summary of the sigillata pots going into the kiln during a single firing event. As a consequence the lists are frequently cited in debates on production organisation. Discussions revolve around whether or not communal firing was practised, how this was arranged, who invested in kiln infrastructure and wood supplies and how norms for quality control were maintained. ${ }^{369}$ But these debates remain open-ended, as the hypotheses are underdetermined by the evidence: e.g. the pattern of stamps and forms may indicate that pots were dried on wooden boards that were then carried to the kiln, but this same pattern could be explained in a myriad of different ways. ${ }^{370}$ The questions of 'who' and 'why' again lead to archaeological dead-ends. Linguistically, the lists mix Latin and Gaulish terms and declensions, and have been studied as examples of bi- or multilingualism with the aim of gaining insight into the social and ethnic dynamics of the potters' community. ${ }^{371}$ Some questions occupying linguists are whether there were Greek craftsmen involved, whether slave labour was used, where the potters came from, and what terminology was used for the pots. ${ }^{372}$

Despite the disciplinary boundary separating those interested in the texts as evidence for language use and those interested in the lists as evidence for production organisation, the scholars involved are united by their general strategy of mining these objects as a source of information about an underlying reality, as retrospective history-tellers. The lists are (often implicitly) read as accounting devices as we know them today, facilitating the calculation of profits and returns, and referring to a social reality (production organisation, language use) beyond themselves. This use of the firing lists as history-tellers is not inherently wrong, but it is at best a partial narrative. Importantly, it misses out on the question of what a fir-

\footnotetext{
365 Bémont/Vernhet 1992/3; Hermet 1934; Lambert 2002, 83-146; Marichal 1988;Vernhet/Bémont 1990/1.

366 Blom 2012; Fülle 2000a, 64-65. P. Webster (2001, 295) hints at a link between the firing lists, the use of large kilns with tubuli and large-scale export, but this remains hypothetical (e.g. no firing lists attested at Lezoux).

367 Charlier 2004; Marichal 1988, 17 ff.
}

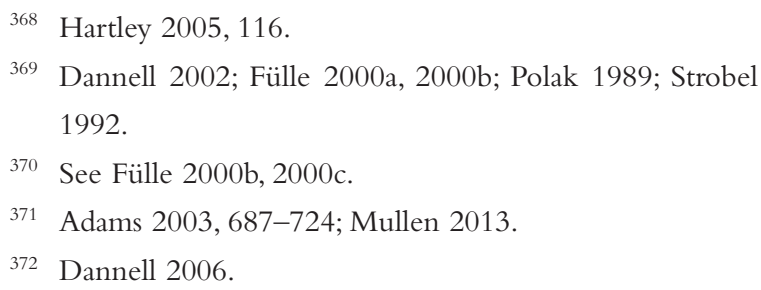




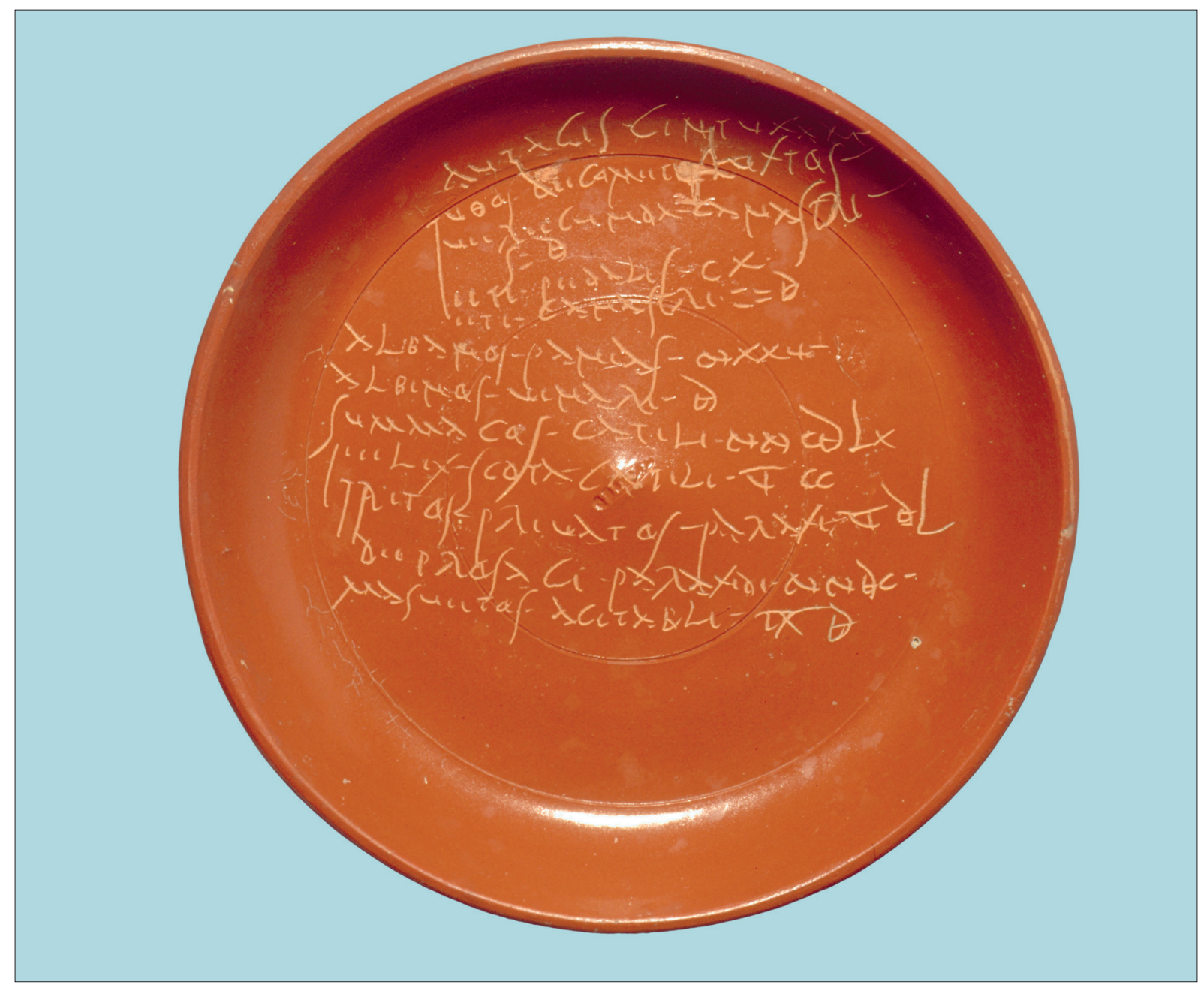

Fig. 4.1. Firing list (bordereau d'enfournement) on terra sigillata plate, written in Latin with Gaulish heading (La Graufesenque (Millau), 1st century AD) (C) Musée Fenaille - Rodez (coll. Société des Lettres, Sciences et Arts de l'Aveyron), photo Gilles Tordjeman (with permission).

\section{Transcription of the firing list from La Graufesenque (Musée de Fenaille)}

\begin{tabular}{|c|l|}
\multicolumn{2}{l}{ heading } \\
\hline 1 & autagis cintux XXI \\
\hline 2 & tuOos decametos luxtos \\
\hline
\end{tabular}

Fig. 4.2 Transcription of the firing list in Fig. 4.1.

\begin{tabular}{|c|c|c|c|c|c|}
\hline & (potter's?) name & vessel form & \multirow[t]{2}{*}{ (adjective) } & \multicolumn{2}{|l|}{ quantity } \\
\hline 3 & uerecunda & canastri & & & \\
\hline 4 & & & $S=$ & D & 500 \\
\hline 5 & (eti) & pedalis & & $c x$ & 110 \\
\hline 6 & (eti) & canastri & $==$ & D & 500 \\
\hline 7 & albanos & panias & & (I)XXV & 1025 \\
\hline 8 & albinos & uinari & & D & 500 \\
\hline 9 & summacos & catili & & (I)(I)CDLX & 2460 \\
\hline 10 & felix scota & catili & & V CC & 5200 \\
\hline 11 & tritos priuatos & paraxi & & V DL & 5550 \\
\hline 12 & deprosagi & paraxidi & & (I)(I)DC & 2600 \\
\hline 13 & masuetos & acitabli & & IX D & 9500 \\
\hline
\end{tabular}


ing list actually did, and how it related to the pots ('sigillata') it described. It follows that we should not limit analysis of the firing lists to what they tell us about the world (history-teller), but we should also ask what role they played in that world, and how they helped constitute it, with particular attention to how they framed possibilities for economic action (history-maker). This latter question requires the lists to be reinserted into the practices of firing and pottery production, and it is to these that I now turn.

\section{2 .2 NEGOTIATING DEFINITIONS AND ROLES}

Sigillata studies tend to gloss over the firing process as a mere organisational hurdle. Once the technology for firing large batches of sigillata in an oxidizing kiln atmosphere was known, it was but a matter of investment and internal organisation to successfully implement it - or so the standard retrospective argument goes. ${ }^{373}$ Experimental studies serve to chart the precise correlations between investment, resources and output in this equation. ${ }^{374}$ The underlying rationale is that the firing of sigillata was mastered by a combination of skill and investment. But is this the full picture?

Ethnographic studies show that firing is one of the most crucial and uncertain stages in pottery production around the world, with a high symbolic leverage. ${ }^{375}$ This fits with a more general enchantment produced by complex technological processes. ${ }^{376}$ These studies amplify functionalist narratives by recasting technology as a meaningful strategy for making sense of the world. ${ }^{377}$ Firing was one of the most uncertain stages in the production sequence of sigillata too. Firstly, firing was irreversible: whatever the outcome, it could not be corrected. This is in marked contrast to previous stages in the production process that led from clay and water to a leather-hard formed pot, which could theoretically still be remodelled into a new sigillata pot. Rejects from firing, however, were dumped on the production site instead of being re-injected into the production process. ${ }^{378}$ As sigillata clays were fine and not tempered, misfired pots could not be recycled as grog. Secondly, firing was an obscure stage, which not only necessitated specialized skills but was also shielded from view as an indirect consequence of the closed nature of the kiln infrastructure, with only narrow access to the firing chamber.

This uncertainty was decisive for the different roles in sigillata production. The first such role is related to craftsmanship as 'doing a good job', and hence to the potter, workshop, or officina as a craftsman/ association of craftsmen. ${ }^{379}$ In contrast to previous stages in the production process, the potter could not directly determine what happened to the pot in the kiln. The direct causal relationship between skilled bodily movements and adjustments to the shape or composition of the modelled clay was cut. As a consequence there was a constant threat of alienation between pot and potter. The pot was both an extension and a self-realization of the potter: if this would fail, then the potter would be both economically and socially discredited. Moreover, if firing was not successful, the pot was rejected and the potter's stamp $p^{380}$

373 Picon 2002b.

374 de Casas/Fernandes 2002; Fernandes/Fernandes/de Casas 2005; Schaad 2007, 219 ff.

375 On ceramic production: Birch Aguilar 2007; Dean 1994; on metalworking: Blakely 2006; Childs 1999; Giles 2007; Haaland 2004; Herbert 1993; Swenson/Warner 2012.

376 Gell 1992, 1998.

377 Dobres/Hoffman 1994; Latour 1991; Lemonnier 1986, 1993; Pfaffenberger 1992.

378 Genin 2007.

379 The literature on craftsmanship is expanding, e.g. Sennett 2008; Ingold 2010
380 The role of the stamps is debated, and is likely to have varied across time and space. In this chapter stamps are linked to the producing parties (potters, officina owners, or workshop groups). Moreover, the correspondence between the names on the firing lists and the attested stamps is only partial: 'of 163 names on the firing-lists only 54 are the same as those of contemporary potters who stamped samian (33 per cent), 87 names are not known on contemporary stamps (53 per cent), and the remaining 22 names (14 per cent) are unlikely on the whole to be related to contemporary stamps' (Hartley/Dickinson 2008-12, 23). Also Oxé/Comfort/Kenrick 2000. 
on its base was knocked out, thus materializing this alienation. ${ }^{381}$ Rejects range from fused stacks found in a ditch at La Graufesenque to pots with minor deviations of cracking, surface finishing, or form. ${ }^{382}$ This demonstrates that the nature of a 'proper product' and the attendant 'craftsmanship' were clearly defined. If however firing was successful, the pot was sold on as a product advertising craftsmanship, and the potter or officina owner became recognized sources of quality pottery.

On the other hand, the stakes in firing for the role of investment in sigillata production were high too. Large kilns and firing infrastructure amounted to a considerable part of funds and know-how, and the firing process crystallized all of the investment in sigillata up to that point (labour, raw materials, skill, etc.). Hence firing also decided whether or not investment and resources would turn into returns. As a consequence, firing connected and tuned two different definitions of sigillata, based on the perspective and the needs of respectively production and investment - regardless of whether or not these roles overlapped (i.e. whether potters actually invested funds themselves).

The firing process was therefore an uncertain moment at which different roles were (re-)defined and the attendant norms were negotiated. Anthropological studies have noted that participation in technical activities is choreographed so as to lead to 'the creation of the type of personhood that the community deems essential to its viability'. ${ }^{383}$ Through the activity, the norms and rules for 'good selves' and 'bad selves', or, in this case, for 'good potters/good investment/good sigillata' and 'bad potters/bad investment/bad sigillata' were negotiated and reaffirmed. This attribution of identities happened regardless of whether or not there was a causal relation between a 'good potter' or a 'good investment' on the one hand and 'good sigillata' on the other: these roles were at stake in a process (firing) they could not fully control. All of this suggests that an interpretation of firing as an organisational stage of sigillata production only covers part of the story.

\section{$4 \cdot 2 \cdot 3$ PRESCRIBING PARAMETERS}

If these different roles negotiated their respective definitions of sigillata through firing, then where did this leave the pots and the parameters by which they were defined and evaluated? This is where the firing lists as history-makers come in: careful reading reveals that their role might not have been limited to documenting production organisation. For example, although most adjectives qualifying the types of pots tend to be specifications of size and dimensions - which makes sense as an accounting measure as the pots would have been stacked in the kiln by size - some adjectives talk about different aspects. ${ }^{384}$ There are several mentions of types of red: aematina ('blood-red' (like opaque red glass)), mi]niata ('coloured with red'), bur[ra ('red'). ${ }^{385}$ Descriptions of a red exterior colour only make sense after firing, after the chemical reactions altered and fixed the exterior colour and hue of the slip. In other words, not only do the firing lists keep track of the pots loaded into the kiln, they also de- or pre-scribe sigillata as the projected end result of successful firing: a pot of a certain form, function, size and colour - a 'good' sigillata pot. ${ }^{386}$ Key for the present analysis are not as much the actual descriptions of the colours and the different shades they denote, but the very degree of specificity that the medium of text allowed for and by which it enabled a fine-grained classification of that which was being described (sigillata). It follows that attempts at reconstructing direct semantic relations between specific terms and specific shades of red slip are in vain - sigillata scholarship tends to be able to distinguish between such shades only in cases of different production centres or radical chronological and technological changes. ${ }^{387}$

381 Dannell 2002, 218, footnote 54.

382 Fosse Cirratus (Genin 2007, 55-70).

383 Pfaffenberger 1999, 153 (original emphasis). Cf. Miller 2008, 58. Budden/Sofaer 2009 for a similar analysis.

384 Marichal 1988, 82-83, who argues that adjectives other than size were mentioned only if size was irrelevant for recognizing a certain type of pot, e.g. for catili and paraxidi.

385 Marichal 1988; Mullen 2013. Bradley 2009 on colour in the Roman world more generally.

386 Cf. Austin 1962 on performative speech acts.

387 Brulet/Vilvorder/Delage 2010. 
A more general tension is evident between the fairly standardized format of the opening formulae and organisation of the lists, and the great variety in vocabulary, with many quasi-synonyms and unique terms. ${ }^{388}$ Moreover, none of the adjectives mentioned on the lists differentiates between what archaeologists have seen as discriminating aspects for the creation and identification of types, for example the profiles of different 'services', the differentiation between plain and decorated bowls etc. This is not merely an issue of etic versus emic categories, as some of these analytical differences reflect markedly different ways of doing in the past. What mattered was not accurately describing the individualizing specifics of every single pot, as much as pre-scribing it as if it was already a successfully fired pot, which could potentially be characterized by its specific traits and distinguished from other pots. The lists thus constituted parameters of definition and evaluation for the finalized product of sigillata. Where the previous chapter described the emergence of sigillata as a category defined by binary boundaries and a package of traits through production practices, the firing lists helped substantiate these traits.

Furthermore, the firing lists materialized a shift in the scale at which sigillata production was conceptualized. During the modelling process sigillata would have been understood based on individual pots, linked to individual potters, workshop units or officinae. Indeed, a potter could only handle a single pot at any one time, however little time needed. By making the sum of the individual number of pots per potter or supplier, the lists enabled this sum total to be understood as a new whole, and, as a consequence, to change the relevant unit from the single pot to the kiln load. What is more, it is likely that this shift was prefigured in the way the firing lists were compiled: internal variation in vocabulary and declensions shows that they were possibly the result of a copy-paste process of a series of shorter notes - some of which have been found. ${ }^{389}$ The rarity of such finds, however, makes it doubtful that this was the regular practice. ${ }^{390}$ In any case, even though a temporary succession of copy-paste may have taken place, both the shorter (delivery or loading) notes and the firing lists were eventually included in the kiln load to be fired, and thus took part in the same uncertain process of firing.

Adjectives and quantification - and the attendant switch in scale - laid down a template for sigillata, which was not neutral but made 'comparable activities and processes that may otherwise have [had] little in common' ${ }^{391}$ By effecting a shift in unit, the firing lists entailed new possibilities for trade: instead of having individual pots trickle through the mazes of distribution, wholesale batches could be sent off after firing. And by pinning down the traits by which the desired end product could be defined - colour, form, dimensions, etc. - with a notable degree of specificity, the lists created possibilities of comparison, measurement and calculation. ${ }^{392}$ The lists thus served to articulate the possibilities for action created by sigillata's definition as a category in production. As a consequence, sigillata defined accordingly could enter into practices that required accountability, comparison, etc. Put differently,'accounting' as a type of action both presupposes and creates kinds of things with the possibility of individual identification (e.g. this specific dish of size $\mathrm{x}$ carrying stamp y), grouping (e.g. all dishes of size $\mathrm{x}$ ), comparison (e.g. potter $\mathrm{x}$ brought a number of dishes of this type, and this is less than potter y), and finiteness (e.g. a finite number of pots can go into a kiln load) ${ }^{393}$ The possibility of using the lists as accounting devices to calculate profits or return $s^{394}$ is thus not ruled out by the analysis developed here - but becomes coextensive with a process whereby the lists constituted the accountability of sigillata itself. Considering things as history-makers again amplifies their potential as history-tellers.

And this is precisely where the La Graufesenque firing lists differ from similar Roman 'tally lists' involved in tile production, which include no description whatsoever of the expected products. If there was any projection of the end result involved, this was of a very different nature, less amenable to internal

388 Marichal 1988, 83.

389 Bémont 2004, 126; Marichal 1988, 103-105 (Mar. 77, 82, 90); Lambert 2002.

390 Dannell 2002, 220, footnote 67.

391 Miller 2008, 58.

392 Callon 1998a; Slater 2002a, 2002c.
393 Cf. Callon's (1998a, 1998b) inquiry into the mechanisms that make neoclassical calculative action possible.

394 As 'eine Art Buchführung' (Fülle 2000a, 63); or as enabling the calculation of profit per potter, as the supplied pots minus the division of costs for marketing and distribution (Nieto 1986, 109). 
differentiation and specification. As a consequence, the modalities of framing the uncertainty of firing, if not the uncertainty itself, have to be seen as specific performances developed in the context of sigillata production. Whether or not this was peculiar to La Graufesenque, or had wider currency among sigillata production sites, and, if the latter, how this practice was transmitted, remains obscure. Fragments of similar lists have been found on a number of other sigillata production sites, but none of these offer any scope for seriously tackling these issues ${ }^{395}$ It is my contention, however, that the way in which the firing lists pinned down defining traits for the end result of 'good sigillata' chimes with sigillata's definition as a category in production practices as described for 2 nd century Lezoux in the previous chapter.

\section{$4 \cdot 2 \cdot 4$ D IS T R I B U T I N G A G E N C Y}

What was it about the firing lists that allowed them to negotiate definitions and roles and to prescribe parameters for sigillata? Put differently, what was the source of action? The previous section has mentioned different ways in which the lists shaped action, which could ultimately be traced back to affordances of a textual and numerical syntax, such as the differentiation they allow for. But more relations can be traced.

The practice of inscribing actual sigillata plates and firing them along with the vessels thus described cannot fully be explained as assuring the authenticity and durability of bookkeeping records, or as outweighing the use of scarce papyrus. ${ }^{396}$ The lists were inscribed on a medium that itself had to undergo the uncertain process of firing in order to be transformed, not from clay into sigillata but from clay into record. A firing list occupied a liminal position relative to the rest of the pots: itself prevented from becoming sigillata from the moment it was inscribed (after the slip was applied and dried), it facilitated the transformation of the kiln load into 'good sigillata'. Inserting the projected outcome of the firing process - the successfully fired kiln load as described on the list - denied the uncertainty and implied institutional confidence in the reality of successful outcome. Moreover, the lists can be argued to have been incorporative of the entire fired sigillata batch. This was enabled by the specific combination between the affordances of the lists-as-things (visually (same shape and colour) and causally (result of the same production process) linked to the other pots) and those of the lists-as-texts (symbolically crystallizing the entire kiln load). ${ }^{397}$ Because the lists indexed the successfully fired pots, but remained themselves at the production site, they prolonged the links between the producers and the pots that were traded on.

But even the combined affordances of text and thing did not fully exhaust the role of the lists as history-makers. With regard to the ancient Greek world, a late 6th century BC black-figured vase painting depicts a workshop of ceramic containers, including the kiln equipped with an apotropaic mask and olive branches. ${ }^{398} \mathrm{~A}$ similar appeal to unaccountable forces to protect the firing process is vividly illustrated in the so-called kiln poem from the Life of Homer by pseudo-Herodotus (variously dated to the 2nd-3rd centuries $\mathrm{AD}^{399}$, or between 130-80 $\left.\mathrm{BC}^{400}\right)$. Of particular interest is the listing of five bad spirits ('ravagers of kilns'), which objectify all that could possibly go wrong in the kiln (cracking, breaking, collapsing of pile, overfiring, distortion). ${ }^{401}$ But above all, the poem attests to the paradox involved in trying to manage firing: scrupulous observance of all necessary steps is needed, but eventually the outcome is still a matter of hoping and waiting, often subject to the whims of unaccountable forces. Accountability is never contained in or guaranteed by the preceding steps, and unaccountable uncertainty does not easily translate into calculable risk. ${ }^{402}$ As Marian Naranjo, a potter in New Mexico, testifies:

395 Marichal 1988, 16; Mullen 2013, Appendix.

396 Marichal 1988, 15-17.

397 Knappett 2002, 2005.

398 Hampe/Winter 1962, 54, 114. I am grateful to Athéna Tsingarida for this information.
Noble 1966, 102.

400 von Wilamowitz-Moellendorf 1916, 413-439.

401 Noble 1966, 103-105.

402 Cf. Hennion 2001, 12 on the framing of an unaccountable or passionate music experience. 
'After you have done everything patiently and carefully, you just hope, until the firing is finished, that all the pots turn out. (...) You have to be real clean about every stage of your work, or else the finished product will not turn out right. Even your feelings have to be real good'. ${ }^{403}$

In other words, there is always something escaping full calculation, and that may be precisely what is needed to make firing work. ${ }^{404}$

This 'something' is also hinted at by the firing lists - differentiating them even further from the Roman-period tallies on tiles discussed above. The opening heading of the lists sometimes contains the term legitumu, referring to some kind of control or legitimization. ${ }^{405} \mathrm{~A}$ control mechanism fits well into the discourse of authenticity and rationality associated with a retrospective reading of the lists as accounting devices. But again the evidence is rather more complex. The term legitumu is associated with casidanos (Gaulish) or flamen (Latin). Much has been written about the 'who' and 'why' behind these parallel terms - in particular flamen, as the etymological roots of casidanos remain obscure. ${ }^{406}$ The interpretations advanced so far identify the terms either as devices for eponym dating or as referring to firing masters. Marichal's hypothesis is that the flamines on the lists are analogous to provincial priests, and are mentioned as a means of eponym dating. ${ }^{407}$ The mention of flamen would thus be primarily a means of dating consecutive kiln firings, and, presumably, of keeping track of the fired batches. Strobel, in turn, traced the etymological roots of flamen back to flamma, emphasizing the link between fire/craft and cult/priests. ${ }^{408}$ As a result, he arrives at an identification of the flamen/casidanos as firing master. ${ }^{409}$ Note that those who are named as flamen or casidanos sometimes also feature as potters in the actual lists.

One way to escape this etymological conundrum is to ask how the text as writing actually enabled and constrained the course of practice. Beard has claimed that the practice of writing shaped the nature of Roman pagan religion and of the possible relations within that religion. ${ }^{410}$ How did the written mention of flamen/casidanos affect the agency of the firing lists, what did it allow them to do?

Mention of flamen or casidanos seems to have gone hand in hand with the inscription of either a cross or a raven on the base of the plate (which by then had become a list). Although its precise connotation is unclear, the raven represented a powerful and ominous force according to Celtic tradition. ${ }^{411}$ In particular, the raven was associated with prophecy and had 'alleged prognostic powers', exceptional intelligence and skills. ${ }^{412}$ These capacities fit remarkably well into a narrative of firing lists as projecting and enforcing an expected future outcome of a process requiring great but obscure skills.

In light of the ample ethnographic and archaeological evidence on the ritual and religious connotations of firing referred to above, it is surprising that scholars have been so reluctant to emphasize this aspect, as both the raven and the term flamen indicate some kind of ritual or even magical capacity. ${ }^{413}$ This betrays a deep-rooted polarization between economics/calculation and magic/ritual, by which the former equals a progressive disenchantment of the latter. ${ }^{414}$ Conversely, as the 'Other' of rational economic action, magic is often defined in wholly constructivist terms. ${ }^{415}$ When considered as practices shaping rather than reflecting possibilities for action, however, the distinction becomes less sharp, and the firing lists suit both accounting strategies and magical practices as a 'kind of coercive proceduralism'
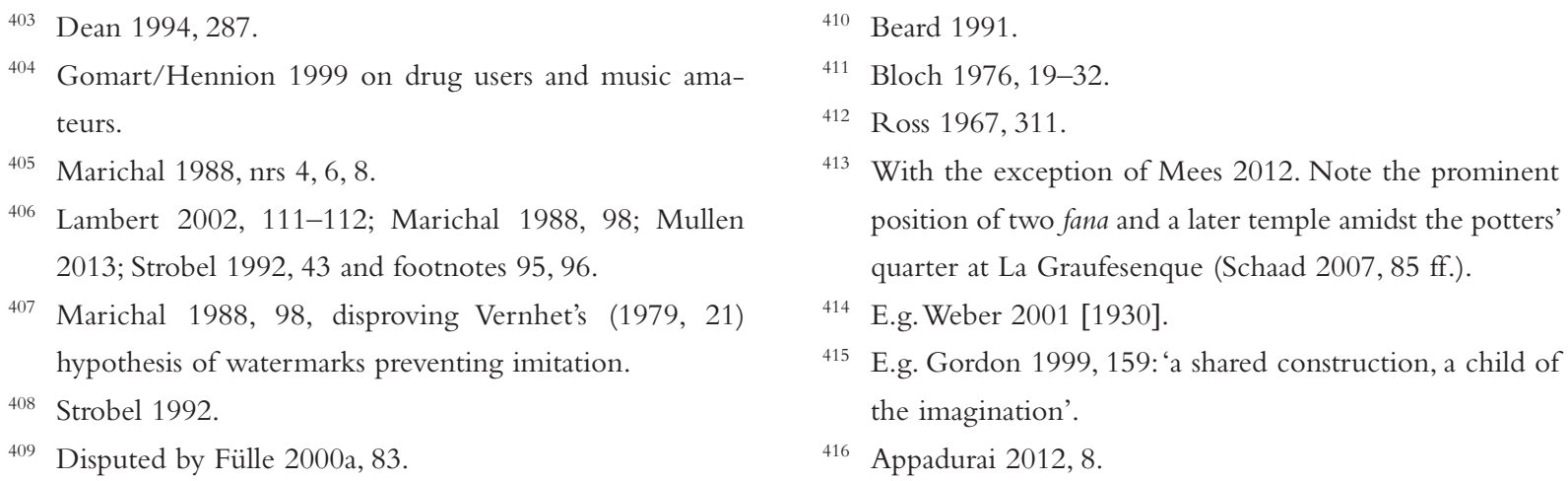
The combination of the formula, the role of flamen/casidanos, and the act of inscribing a cross or raven should be seen as a ritual acknowledgement meant to bring about the desired end result of successful firing: sigillata pots with a well-defined package of traits (colour, shape, size, etc.). As such this 'ritual' practice eventually enabled the definition of sigillata as a category, facilitating comparison and calculation, and thus its enrolment in 'economic' transactions.

It is thus impossible to pin down a single source of action. As soon as agency is located, it escapes, from the text, to the thing, to unaccountable forces and priests. Firing lists were at the intersection of a network of practices that as a mechanism - not as a source of action - framed the uncertainty of the firing process and compelled a specific end product. More specifically, it pinned down the defining traits that make up the package of the category of sigillata.

\subsubsection{A PATCH W ORK OF PRACTICES}

The previous section has examined what the firing lists did by inserting them in the practice of firing. But the lists were enrolled in a patchwork of further practices, including practices of production and deposition.

Firing lists did not exist as such before inscription, which set them apart from the remainder of the batch of pots to be fired. Because they were themselves written on pieces of 'sigillata in the making' (before these became 'sigillata as a category' through firing), the lists had a continuing, incorporative relation to the batch in question. This link was further reinforced and specified by the text, which defined the projected end result as a kiln load of fired sigillata of particular shape, size and (sometimes) colour. But the text can also be considered as an engagement in material practices, as an act of writing. ${ }^{417}$ As material engagement, carving lines in cursive writing is very similar to carving lines when drawing crosses or ravens; especially since both used the same medium of leather-hard clay. Here too the practice, the very act of doing, constructed a meaningful, active link. The crosses and ravens come in different types, with various 'hands' producing variations on a shared template. While the ravens for instance are always drawn facing the same direction and following the same broad hand movements, they range from schematic depictions to very detailed elaborations, including feathering on the feet. The combination of a more or less formalized template with considerable latitude of variation in its actual contents reiterates the same tension observed with regard to the vocabulary and formulas used in the text. The connection thus established tied together sigillata as the expected outcome (written as text) and the unaccountable forces called upon to compel this outcome (drawn as ravens).

What if things went wrong, if one of the links did not perform? Rejects with knocked out stamps were mentioned above. But what happened when the misfired pot was the firing list itself? Unfortunately we are bound to speculate on this point, as no example of a misfired or rejected list has been retrieved. One fragment of a firing list has a central gap partly erasing the stamp, but the dented edges suggest that this was caused by post-depositional processes rather than by the knock of a sharp object. ${ }^{418}$

In fact what happened to the lists after firing remains unclear. Hermet unearthed the most complete lists at the start of the 20th century. Precise contextual and stratigraphic information on these finds is lacking, but on the basis of excavation notes and plans it can nevertheless be posited that they originated from two close but distinct findspots. ${ }^{419}$ Bémont even speaks of a kind of 'dépôt' or repository where each example of those firing lists would have been kept in a good state. ${ }^{420}$ Later excavations by Vernhet using more accurate registration procedures yielded a substantial additional number of graffiti, but all of a more

417 Ingold 2007a, 2007b.

420 Bémont 2004, 114.

418 L-30g: Lambert 2002, 97.

419 Dannell 2002, 215; Marichal 1988, 3-6. 
fragmentary nature. ${ }^{421}$ Some seem to have been deliberately broken, for example to repair the fill of a road crossing the workshops. Even though it is clear that Hermet picked out the nicest, most complete examples, it is nevertheless remarkable that no well-preserved lists have been found in any of the recent excavations. ${ }^{422}$ This pattern of finds seems to point towards different modalities of treating the lists after firing, possibly in relation to the outcome of the firing process, i.e. how well the lists had performed, by the parameters they themselves had set. Could it be that a firing list that did indeed manage to steer the firing process to a successful end result was kept and filed, while one that had failed to do so was itself destroyed?

\subsubsection{FROM CATEGORY TO COMMODITY}

The firing lists not only represented or documented a world outside (e.g. production organisation, potters' community), but actively helped constitute this world and the possibilities for action in it. More specifically, the lists aimed to stabilize the uncertain but crucial process of firing by inscribing the projected end result of successful firing. This expected end result was 'good' sigillata, characterized by well-defined forms of certain size ranges, with specific kinds of red colour, etc. As such the firing lists continued sigillata's definition as a category as enacted in production practices. These 'good' sigillata pots in turn affirmed the craftsmanship of their potters, workshops or officinae and were the basis of the profits of those who had invested in the production. In sum, firing acted as a bottleneck for negotiation and affirmation of what counted as sigillata and what did not, and the firing lists were active gatekeepers of these standards.

While the previous chapter already discussed comparability as one of the consequences of sigillata's definition as a category, this can now be extended to accountability and commodity exchange. Accountability is not an a priori of a certain economic system (e.g. market-oriented commodity exchange), but arises as a function of a specific set of practices. The accountability of the firing of sigillata - and, as a consequence, of sigillata itself - had to be carefully performed. The firing lists had a leading role in this performance of reducing the uncertainty of firing and of pinning down and compelling certain attributes of the expected finished products. While sigillata was being defined as a category with a binary boundary and an identifying package of traits through production practices, the firing lists further articulated these traits and paved the way for these pots to be exchanged as commodities. Sigillata was made into a tradeable commodity by configuring the attendant roles (e.g. investment) and parameters (e.g. sizes), which in turn enabled certain kinds of economic action (e.g. comparison, calculation). The firing lists lined up roles, successfully closed the production sequence, and provided a template for the resulting products, thus facilitating the products' exchange. The conditions for economic action, social roles, and relations of meaning and power are all coextensive and negotiated through material practices. Within such an approach the firing lists' appeal to ritual, for example, no longer precludes an outcome of economic calculability and commodity exchange.

\subsection{Sigillata ON THE MOVE: CHANGING PARAMETERS AND T H E K I L N L O A D M O D E L}

Following the trajectory of a fired batch of sigillata from La Graufesenque onwards, this chapter enters the more traditional grounds of ancient economic history. The starting point is sigillata defined as a category, whose package of traits has crystallized, and whose relations to production have been cut. At this stage, sigillata was ready to enter into commodity exchange. But commodities were not singularly

421 Marichal 1988, 6-8.

422 Schaad 2007. 
defined either. Instead, at different stages in sigillata's distribution, different situational parameters prevailed, and different characteristics from its defining package of traits were foregrounded. Four rare sets of unused sigillata allow probing four different stages in the exchange of 1st century AD sigillata from La Graufesenque: an assemblage from Port-la-Nautique near Narbonne, a shipwreck (Cala Culip IV) off the Catalan coast, two Colchester 'pottery shops', and a crate of decorated sigillata in a house in Pompeii (Fig. 3.2 for location of these assemblages).

\subsection{INTERMEZZO： S I GILLATA PRODUCTION ORGANISATION}

Vigorous debates have been waged over the riddles of sigillata production organisation, in particular focusing on evidence of stamps and firing lists from La Graufesenque. Throughout the 1st century AD, most sigillata forms carried an epigraphic name stamp on their inner base. Stamps with different readings referring to the same name are separated out as individual dies. All stamp and die numbers used in the following analyses are based on the Leeds index as published in Names on Terra Sigillata by Hartley and Dickinson (2008-2012). The exact role of the stamping practice remains a bone of contention, and was in all likelihood subject to chronological and geographical variation. As stamps were applied before firing, at the very least they can be taken as a generic index of the production process. But just what form this index took is unclear, and different interpretations feed into different implicit assumptions about the organisation of sigillata production, and, on a bigger scale, about the nature of the Roman economy. Sigillata production organisation has been described on a sliding scale from industry ${ }^{423}$ or manufacture ${ }^{424}$, to nucleated workshops ${ }^{425}$, or even 'artisanat groupé'. 426

This prequel does not aim to get into the nitty-gritty of the debate, which remains largely beyond empirical testing. But before developing the case studies below, I need to sort out some of the practicalities involved in the organisation of sigillata production. Firstly, it would have been normal practice for sigillata kiln loads to contain pots made by different potters, workshops, or officinae (i.e. carrying different stamps). This follows from the sheer volume of some of the kilns such as the grand four at La Graufesenque (measuring $7 \times 7 \mathrm{~m}$ ), from the organisation of the firing lists with separate lines headed by different names, and from deposits at the production site such as the Fosse Cirratus containing fused stacks of pots stamped with different names. ${ }^{427}$

Secondly, it is very unlikely that individual potters or workshops would have claimed their pots after firing, and would have organised distribution themselves. Ethnography of installations of similar size shows that the making and selling of pottery are generally separate activities. ${ }^{428}$ But there is also the practical difficulty of identifying and retrieving standardized pots from a fired batch. Granted, those responsible for the firing would recall how the pots were arranged in the kiln, and stacks would have been organized by form. But the sheer number of pots fired would have made this post-firing retrieval a very tiresome business indeed. Moreover, the tiny format of the stamps argues against this option, as does the fact that pots would have been stacked base-upwards, which would have made the stamps on the inner base invisible. Finally, the geographical distribution of stamps from La Graufesenque does not show the regularity one would expect if individual workshops arranged for distribution on the basis of personal trade networks. In contrast, such a pattern has been attested for the 1st century BC distribution of Italian sigillata produced in different workshops at Arezzo. ${ }^{429}$

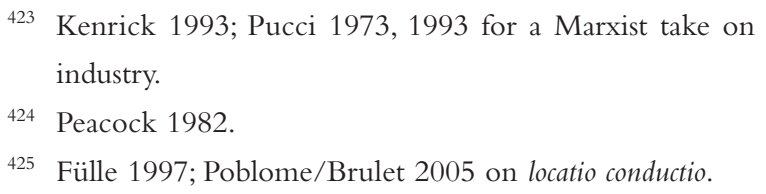

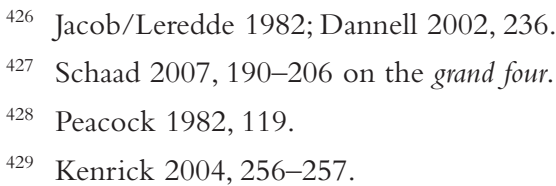


This goes to show that communal firing does not need to imply a cooperative-like production organisation, with equal and autonomous potters. As mentioned in the previous chapter, investment probably forms the key missing link. My working hypothesis, therefore, is one where landowners provided the necessary influx of capital, and established some form of contract with the potting community, however the latter was organized internally, and whether this contract was based on rent or output. Decisionmaking with regard to means and output would then reside in the node between investors and traders, while the potters possessed the know-how and organised the actual production practices.

\section{$4 \cdot 3 \cdot 2$ P ORT-LA-NAUT I Q UE: REG ULAR T URNOVER}

Although the importance of Narbonne as a commercial port is well attested in ancient texts, researchers struggle to link this to an unequivocal archaeological picture. ${ }^{430}$ Narbonne was separated from the Mediterranean by briny lakes. These acted as a buffer for coastal transport, but they were also under constant threat of silting up. The current hypothesis posits a possible fluvial port in Narbonne itself ${ }^{431}$, and multiple (temporally consecutive?) outer sea harbours along the lakes where goods could have been transhipped on flat-bottomed vessels. The only candidate identified as yet for the latter function, however, is the site of Port-la-Nautique, along the northern shore of a lake, four kilometres south of Narbonne. Dredging works have identified a short activity period between $40 \mathrm{BC}$ and $\mathrm{AD} 70$, but some recently retrieved Greco-Italic amphorae might push this back as far as 150 BC. ${ }^{432}$ Significantly, if Italian sigillata is found - mostly in relation to the early 1 st century AD - it bears traces of use and graffiti, distinguishing it from other materials found in the port area that were clearly part of commercial cargoes. ${ }^{433}$

One of the only stratified assemblages at Port-la-Nautique has been excavated in a silted, now inland zone that would have been at the waterfront in the 1st century AD. ${ }^{434}$ The assemblage resulted from a test sounding to the west of the ruins of a large building with tiles and antefixes, then identified as warehouse, but later reinterpreted by some as domestic structures or exploitative villae. ${ }^{435}$ Later excavations east of the test sounding unearthed remnants of a large structure along the shore, poor in archaeological material, and identified as a warehouse for storage purposes. ${ }^{436}$ One of four identified layers contained about 300 $\mathrm{kg}$ of generally reconstructable sigillata forms, interspersed with few single sherds from amphorae and other ceramics and a coin dated to the reign of Claudius. Based on the stratigraphy and reconstruction of the assemblage it is clear that the ceramics form a homogeneous batch of complete and unused sigillata vessels that has been discharged in one go, between $\mathrm{AD} 50$ and $60 .{ }^{437}$

The stamps and overall appearance of the vessels suggest a provenance from La Graufesenque, echoing what is known about that centre's distribution and marketing strategies. ${ }^{438}$ Pots were brought to Narbonne overland over the causse $d u$ Larzac, where they were either shipped in sea-going vessels for trade within the Mediterranean, or set out for a northwards route along the Rhône. One of the graffiti found at La Graufesenque gives some hints regarding the modalities of the first stage of overland transport from the production site, relating the activities of six slaves owned by a certain Atilia. ${ }^{439}$ Reference

430 Strabo, Geographia IV, 1, 6, 12; Diodorus Siculus, Bibliotheca historica V, 38; Sanchez 2002.

431 Sanchez 2009, $300 \mathrm{ff}$.

432 Sacnhez 2009, 265, 279; Bouscaras 1974; Solier 1981.

433 Sanchez 2009, 275.

434 Fiches/Guy/Poncin 1978.

435 Sanchez 2009, 271 (based on fragments of wall-paintings, domestic waste and oyster shells).

436 Sanchez 2009, 272-274, Fig. 209 (reports unpublished).
${ }^{437}$ Fiches/Guy/Poncin 1978, 187, Fig. 2. Dating based on stratigraphy, stamps and form ratios.

438 Only Salvius is attested at Montans instead of La Graufesenque, while the production of a few others (e.g. Dioratus) has not yet been localized (Fiches/Guy/Poncin 1978, 193). Montans generally distributed its products westwards (Martin 2001).

439 Marichal 1988, 226-227, nr. 169. 
is made to transport to a number of places, including the number of days needed, and a general mention of ad $m[$ ercatum $]$ has been reconstructed in association with a 'mule driver'. ${ }^{440}$ In short, the first stage of transport was being 'catered for within the context of traditional market locations and without the need for the creation of a novel and specialized marketing network'. ${ }^{441}$ Some form of leasing contracts (locatio conductio) can be hypothesized, but scholars are bound to speculation when it comes to identifying the actual legal agents. ${ }^{42}$

Can an inquiry into how sigillata was defined between the production site and the warehouse at Narbonne move beyond speculation? First of all, sigillata was not understood by reference to something else; space on the mules did not have to be shared with other products; risk (e.g. breakage or theft) pertained solely to the bright red pots newly produced at La Graufesenque. The cargo equalled sigillata, and, more specifically, sigillata from a single production site, La Graufesenque. The assemblage from Port-la-Nautique illustrates that this understanding of sigillata as a prime product in and of itself remained unaltered through storage in the warehouses: the stored piles that were dumped contained solely new sigillata pots.

It is possible to go even further and suggest an equation between the cargo transported overland and a single kiln load. Returning to the firing process, the previous section discussed how it altered the scale at which sigillata was made sense of: from individual pot to kiln load. Did this unit remain unchanged throughout transport to Narbonne? In other words, was a single kiln load transported as a whole instead of being fragmented or being temporarily stored at the production site? Several indications seem to suggest so. Nieto emphasizes the time pressure resulting from an overlap in seasonality between the firing of sigillata (between April and September, judging from the firing lists) and favourable conditions for shipping on the Mediterranean. ${ }^{443}$

But the strongest strand of evidence is that of the potters' stamps. The assemblage from Port-laNautique yielded 428 stamps made by 90 different dies and mentioning the names of 53 potters. ${ }^{444}$ The internal division of the number of stamps per potter is interesting (Fig. 4.3), as more than half of the assemblage stemmed from only eight workshops, while about fifteen stamps are only represented once. ${ }^{445}$ The mass of the assemblage stored at a certain point in time in a warehouse at Port-la-Nautique thus consisted of the output of a limited series of potters, very much analogous to what can be reconstructed as (part of) a single kiln load based on the firing lists. It is true that the division of the quantities mentioned on the firing lists by potter varies, from a highly skewed (a single potter accounting for almost half of the assemblage ${ }^{446}$ ) to a fragmented distribution (with lots of smaller entries by different potters). Nevertheless, for any sigillata assemblage en route, one can still reasonably recognize the degree of closeness to one or multiple original kiln load assemblage(s): the difference between multiple contributions to a single kiln load will always be of a much smaller order of magnitude than if we are dealing with mixing of already subdivided lots. ${ }^{47}$ The logical consequence in the case of the Port-la-Nautique assemblage is that the homogenous subset (one or more kiln loads) had been transported as a whole to Narbonne, remaining indivisible throughout the journey. ${ }^{448}$

440 Nieto 1986, 112-113 identifies this 'market' as Narbonne. Given the modality of transport and the time ranges mentioned, however, I am inclined to map these 'marketplaces' onto intermediate stages, as per Middleton 1980, 189.

${ }^{441}$ Middleton 1980, 189.

442 This brings us back to debates on production organisation, as per Nieto (1986; Nieto et al. 1989: 197-206) who claims that trade up to Narbonne was in the hands of a partnership of potters. Speculations on the agents of trade abound, in particular on the role of the army (direct (Wells 1977a, 1977b, 1992) or via metal procurement (Middleton 1980, 1983)).

${ }^{443}$ Marichal 1988; Nieto 1986, 108. Cf. Horden/Purcell 2000.

444 Also Rhodes 1989, 51.

445 Fiches/Guy/Poncin 1978, 190.

446 E.g. Masuetus in Hermet 1934, nr. 3.

447 Contra Walsh 2006, 231.

${ }_{448}$ Nieto 1986, 108. 
Sabinus iii 21a

Senecio 8 a

illiterate

Primus iii 46]

Albinus iii 5 a

Primus iii 21j

Regenus 3-a

Modestus i 4 e

Quintus iii 9a

Cosius Urappus 1a

Albinus iii 4a

? 0.BI

Cotto i 3-a

Cocus i 11a

Cotto i $4 b$

Damonus 14c

Dior-2a
illiterate

Modestus i $9 \mathrm{~g}$

Acutillus 1a

Cotto i 6-a

Gallicanus ii 10 a

Paestor 2a

Bassus ii $4 \mathrm{j}$

Modestus i 26b

Modestus i $4 \mathrm{~d}$

Salvetus i $11 \mathrm{~h}$

Silvanus i $17 \mathrm{~b}$

Ardanus 4a

Bassus ii $7 \mathrm{~b}$

Felix i 24a

Festus i $4 a$

Scotnus $4 a$

Acutus i 30b

Gallus ii 6 a

Lartius 1a

Senecio 8b

(IRTVS)

unidentified

Albanus ii $10 \mathrm{~b}$

Damonus 151

Festus i 6a

Licinus $49 \mathrm{~b}$

Silvanus i 15b

Silvanus i $3 c$

Silvinus i 1 a

(TERTIUS.FE)

Albinus iii 4c

Bassus ii 13b

Bassus ii $4 \mathrm{c}$

Bellicus i 6a

Capito i 1a

Carillus ii 2 a

Carillus ii 2a

Chrestus 8a
Cocis 1a

Cocis 1a

Dab(i)us 1-a

Damonus 13m

Damonus 11e

Darralntus) 2a

Firmo i (9-a)

ngenuus ii $13 b$

lucundus ii $6 c$

lucundus ii $6 c$
Licinus $25 c$

Licinus $25 c$
Licinus $39 b$

Licinus $39 \mathrm{~b}$

Manertus 3a

Martialis i 11a

Martialis i 6a

Quartus iii 8a'

Melain- 1a

Modestus i 2d

Modestus i $2 d$
Primus iii $46 \mathrm{i}$

Primus iii 46i
Primus iii $12 \mathrm{e}$

Primus iii $12 \mathrm{e}$

Primus iii 12n

Primus iii 120

Primus iii $18 \mathrm{j}$

G. Salarius Aptus 10a

Senilis i $2 b$

Silvanus i $6 \mathrm{~b}$

Silvanus i $6 \mathrm{~b}$

Labio 3a
Labio

Labio 3b

unidentified

unidentified

unidentified

unidentified
Fig. 4.3. Stamp distribution by die, Port-la-Nautique (AD 50-60). Data in Appendix 1, Table 1.

The more singular stamps in the remainder of the assemblage, however, indicate that this indivisibility was challenged upon arrival in the warehouse. Since some of the vessels in the assemblage from Port-la-Nautique were still piled up, they must have been dumped straight from the warehouse or storage space. It follows that within that warehouse the new kiln load(s) coming in as an indivisible unit was mixed with sigillata pots from previous deliveries. Because the latter were represented in the assemblage by a random distribution of stamps, a likely scenario is that the bulk of the batches (singular kiln loads) to which they originally belonged had been sold or traded on. ${ }^{49}$ So sigillata underwent another process of transformation - from a determined and bounded indivisible kiln load to a constantly changing 'stock in the making' - although the actual mechanisms (registration, infrastructure, ownership) facilitating this transformation are difficult to pin down. This shift also served to cut the final ties between production centre and products: by dissolving the 'kiln load' as accounting unit, the referential link to kiln, firing, and production was obliterated.

Can a closer look at the internal division of the stamps add anything to this picture? Fiches, Guy and Poncin have sorted the stamps by vessel form - with the inclusion of a generic category of plates/dishes when no differentiation could be made between the bases of Drag. 15/17 or Drag. 18 (Appendix 1, Table 1). To take the most commonly occurring names: 32 stamps of Modestus i are divided over four forms, including a single Drag. 29; 36 stamps by Primus iii encompass five forms, but with a marked predominance of two of them, while two forms are represented by 2 specimens only; 25 stamps naming Albinus iii include 4 forms, one of which with a single specimen; and 24 mentions of Senecio are limited to one single form, Drag. $24 / 25$. So not only was there a skewed distribution of potters (or workshops) in relation to the number of a similar stamp distribution with a 'tail' occurring at Fosse Cirratus, a dump of fused sigillata kiln wasters. It is unclear, however, whether only those stamps represented by many examples occurred on fused pots that can actually be traced back to an intial kiln load. 
of vessels represented, the stamps by those potters represented by the highest number of vessels also show a skewed distribution in relation to vessel form. So those few vessels stamped by potters rarely occurring within the assemblage as well as those vessels with a combination of form and potter's name represented by only a few examples are likely to have been residual pots from (a) kiln load(s) previously brought to Narbonne. A similar pattern can be detected when differentiating individual potters' stamps by die. The 24 examples of form Drag. 24/25 by Senecio were stamped by two different dies: die 8a accounts for 21 specimens, but die $8 \mathrm{~b}$ only for 3 . Again, one could hypothesize that these derive from different original kiln loads.

Further implications for the organisation of production at the kiln site will follow below. For now it is worth noting that it is impossible to differentiate chronologically between the two groups thus identified, as this temporal sequence of individual kiln loads being brought into the warehouses at Narbonne in all likelihood followed the rhythm of firing. Hence the chronological difference between consecutive batches would have been in the order of weeks or months, a resolution too fine for the mazes of dating based on stamps and forms. Only numerical analysis offers scope to tease out the rhythm of input of kiln loads in the warehouse and output of pots for shipment, and I will term the method for doing so the 'kiln load model'. 450

Firstly, although the distribution of number of stamps per potter is skewed, it is not steeply skewed; or rather, it is multimodal (Fig. 4.3). The multiple, but flattened-out peaks of the curve are the remnants of multiple kiln loads being mixed into the assemblage. The large range of variation, and the rather small quantitative differences between consecutive 'peaks' argue for a regular rhythm of turnover. Secondly, the total number of pots per potter is many times smaller than the numbers given on the firing lists from La Graufesenque, which tend to be in the order of hundreds or thousands (pots of a certain form associated with a single (potter's?) name). ${ }^{451}$ These two observations suggest that the assemblage dumped at La Nautique consisted of a random sample of unsold 'leftovers' from a warehouse, representing several instances of kiln loads being brought in and stock being sold on, rather than an aggregate of pots that were rejected upon loading a ship. ${ }^{452}$

But more was at stake in how the warehouse (and its practices) changed the definition of sigillata. From kiln to warehouse, the sigillata-on-the-move had one clear goal: to reach Narbonne. A clear sense of directionality was associated with sigillata: they were originally from La Graufesenque and travelling to Narbonne. This entails unequivocal parameters for evaluation: either sigillata did reach Narbonne and was registered and stored in a warehouse, or not. Once stored in the warehouse and undone from its referential ties to the production centre, this directionality was blurred, and sigillata's movement was halted. Its destination - the 'to' - became uncertain, both in time (when would it leave the warehouse) and space (where would it travel). The assemblage of Port-la-Nautique testifies to this uncertainty, as it never made it through storage. In this case, sigillata's trajectory was probably disrupted for contingent reasons that elude us now - e.g. no more space to fit in a cargo, repurposing and emptying of a warehouse, etc.

\section{$4 \cdot 3 \cdot 3$ CALA C ULIP IV: RECENT REPLENISHMENT}

Evidence for a following stage in the distribution sequence comes from the extraordinary find of a shipwreck just off the coast of Catalonia, north of Ampurias (Fig. 3.2). At the site (Cap Creus) the coast curves outwards, which, in combination with the prevailing winds and currents, would have resulted in a highly dangerous point for ships. ${ }^{453}$ Hence the five shipwrecks of Roman date (Cala Culip I-V) found

450 There are obvious similarities between the arguments of Dannell/Mees 2013 and my approach, developed before the former's publication.

\footnotetext{
451 Marichal 1988.

452 Fiches/Guy/Poncin 1978, 188.

453 Nieto 1986, 82-86.
} 
in that zone, of which Cala Culip IV is the only one presenting a consistent, non-dispersed assemblage. Culip IV - dated to the reign of Vespasian ${ }^{454}$ (third quarter of the 1st century AD) - was a small- to medium-sized ${ }^{455}$ vessel whose main load consisted of Dressel 20 olive-oil amphorae from Baetica (MNI 76) with a joint consignment of Baetican thin-walled pottery (MNI 1500) in addition to South-Gaulish terra sigillata (MNI 1974 (plain) +753 (decorated)) and a small batch of lamps produced in the area of Rome (MNI 42). ${ }^{456}$ A very small number of other amphora types ${ }^{457}$ is likely to have been part of the cargo as well, whereas other singular objects have been identified as the crew's equipment ${ }^{458}$ based on their nature, location and traces of use.

The reconstructed movement of the goods is subject to debate. The model proposed by the excavator runs as follows. ${ }^{459}$ Larger ships with less mixed cargoes would have circulated key products directly among major port hubs. These hubs in turn acted as redistributive nodes catering for a smaller-scale network of trading routes and centres. Hence the olive oil contained in the Dressel 20 amphorae would have been shipped straight from Baetica in South Spain to Narbonne in South Gaul, which acted as a redistributive hub in the 1st century AD. The Baetican thin-walled vessels could have piggybacked on this large-scale transport of staple goods. Upon arrival at Narbonne this cargo would have been unloaded, and possibly temporarily stored, before being transhipped onto a smaller vessel as part of a more mixed assemblage of goods; in this case, including lamps that had come (maybe piggybacking too) to Narbonne from Rome, and a batch of South-Gaulish sigillata. As such a smaller vessel, Culip IV was on its way southwards from Narbonne, following the coast of Catalonia when it was probably overtaken by a storm. Its precise destination(s) can only be guessed, but Ampurias is a likely candidate: because the latter no longer functioned itself as a major hub in this period, it largely depended on Narbonne for its supply of all things Mediterranean. This explains why a ship seemingly moving Baetican products back to their origin (southwards) does not necessarily defy the logic of transport costs.

Millett has suggested another model for the movement of the goods on board Culip, based on the practice of cabotage or coast hopping. ${ }^{460}$ This type of trade whereby ships with mixed cargoes travelled small distances in between stops, trading bits and pieces of their cargo as they went, is in accord with the structural conditions of the Mediterranean and their impact on ancient trade. ${ }^{461}$ Incomplete information, fragmented units, volatile weather and winds, would all have pleaded in favour of a sequence of smaller, changeable, and opportunistic movements. Directional long-distance shipping routes would only have been possible if these structural constraints were subdued by an external agency such as the state. But state supply and the long-distance routes it generated would have been directed towards Rome and the frontier zones. ${ }^{462}$

These different models do not make a major difference to how sigillata would have been defined on board Culip IV. Nevertheless it is worth invoking them as they illustrate how retrospective accounts - assuming that sigillata was the same thing throughout its distribution chain - run into the limits of using sigillata as a history-teller. In view of these retrospective limits, certain a priori's are accepted (e.g. whether or not an external agency like the state was needed to deal with the structural parameters of the ancient Mediterranean), which force the debates on the Roman economy into a stalemate around

454 This postdates the Port-la-Nautique assemblage, but the general chronological horizon and same origin of the pots guarantees the reconstruction of a meaningful trajectory of sigillata.

455 Estimated carriage capacity ca. 8 tonnes; length ca. 9,5 m (Nieto et al. 1989, 229-230).

456 Data derived from report by Nieto et al. 1989. See also Picon 1986.

457 Recorded amphorae other than Dressel 20 all originate from Baetica or Narbonensis, except for one Dressel 2/4

africana (Nieto et al. 1989, 74-76, 82).

458 Nieto et al. 1989, $215 \mathrm{ff}$.

459 Nieto et al. 1989, 239 ff.; Nieto 1986.

460 Millett 1993 and pers. comm.

461 Horden/Purcell 2000. Arnaud 2005 advocates structured sequences of shorter routes.

462 Hopkins 1980. 
that would always have surpassed supply: these pots could be sold anyway, but at a lower price. ${ }^{471}$ This explanation hinges on a strictly modernist economic rationale that fails to appreciate the different kinds of economic 'calculation' ${ }^{472}$ and the changing parameters by which sigillata was defined and evaluated along its trajectory. Once these pots had managed to slip through the mazes of presumed post-firing control, their rejection or acceptance as proper products did not primarily revolve around the quality of their execution (as craftsmanship), but around their size, volume and weight. This meant that what archaeologists now recognize as 'perfect' and 'imperfect' pots did not necessarily come with a different risk for rejection at this stage.

Some pots were still piled up when found. One pile in particular is notable: three Drag. 37 bowls and two Drag. 29 bowls were contained one in another, from large to small so as to minimize the space occupied. Interestingly the excavators encountered a thin-walled vessel (form Mayet XXXIX) as top of that pile on the seabed. In an earlier publication, Nieto accepted this constellation as a reflection of the original situation during transport ${ }^{473}$, but later the team was inclined to invoke the post-depositional action of the sea to have caused the thin-walled vessel to slip onto an original pile of decorated sigillata ${ }^{474}$. Although plausible, this argument seems to contradict indications of the limited post-depositional displacement by the sea on the remains of the Culip IV wreck and cargo. Following the logic of space/ volume it would make sense to allow for 'mixed-type' piles, organized solely on the basis of dimension. Sigillata and thin-walled vessels were both conceptually and practically merged as secondary products in the setting of the Culip IV cargo, and it would have made perfect sense for them to be piled up alongside one another, or even intermingled. Whether or not 'mixed' piles were common practice, the overall distribution of material shows that the concentrations of thin-walled ceramics more or less overlap with those of sigillata. ${ }^{475}$

Product differentiation within the cargo thus did not equal the ceramic classes as distinguished by archaeologists, nor did it hinge on origin as with the previous stage of directional trade. The idea of directionality was loosened; it was no longer limited by the unequivocal and defining 'to' and 'from' as it had been until sigillata reached Narbonne. Directionality was further negotiated with the environment, not in the least winds and seasonality. As mentioned above, both the firing season and the shipping season of sigillata would have coincided during the summer months. Stones of peaches found among the crew's equipment in the Culip IV wreck show that this was no exception to this rule, and that its last journey took place during summer. ${ }^{476}$ The interplay between winds, geography and sea currents facilitates navigation westwards along the northern shores of the Mediterranean and eastwards along the southern coast. ${ }^{477}$ The north-south movement of Culip IV along the western edge of the Mediterranean thus made sense in terms of environmental affordances. Moreover, the properties of a smaller-sized ship like Culip IV necessitated such an increased negotiation with a wider range of actors. It is thus likely that any destination that had been set (probably Ampurias or its region in this case) became a more fluid notion than in a previous stage of directional trade: 'Ampurias' could possibly be replaced by 'the region of Ampurias', or 'some other suitable place on the way to Ampurias where the goods can be sold'. Emphasizing such negotiation does not rule out cabotage as a model; but neither does it mean identifying an 'anarchic' trade pattern, which Nieto is at pains to denounce. ${ }^{478}$

The Culip IV sigillata assemblage shows a stamp distribution similar to La Nautique (Fig. 4.4; Appendix 1, Table 2) in which ' 23 of the 46 potters identified are represented by only 1 or 2 examples. The remainder of the potters are represented by a maximum of 1001 examples, but only 4 potters occur

471 Nieto 1986, 107; Nieto et al. 1989, 161.

472 Appadurai 2012; Callon/Latour 2011; Miller 2008.

473 Nieto 1986, 102.

474 Nieto et al. 1989, 179, 187-189.

475 Distribution of thin-walled ceramics: Nieto et al. 1989,
109.

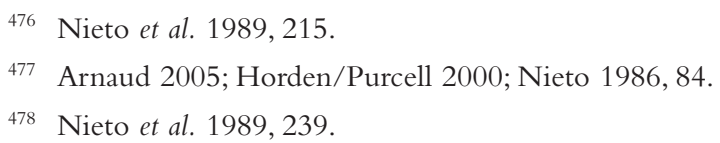

476 Nieto et al. 1989, 215.

478 Nieto et al. 1989, 239. 
Caia Culip IV

Number of stamps per die

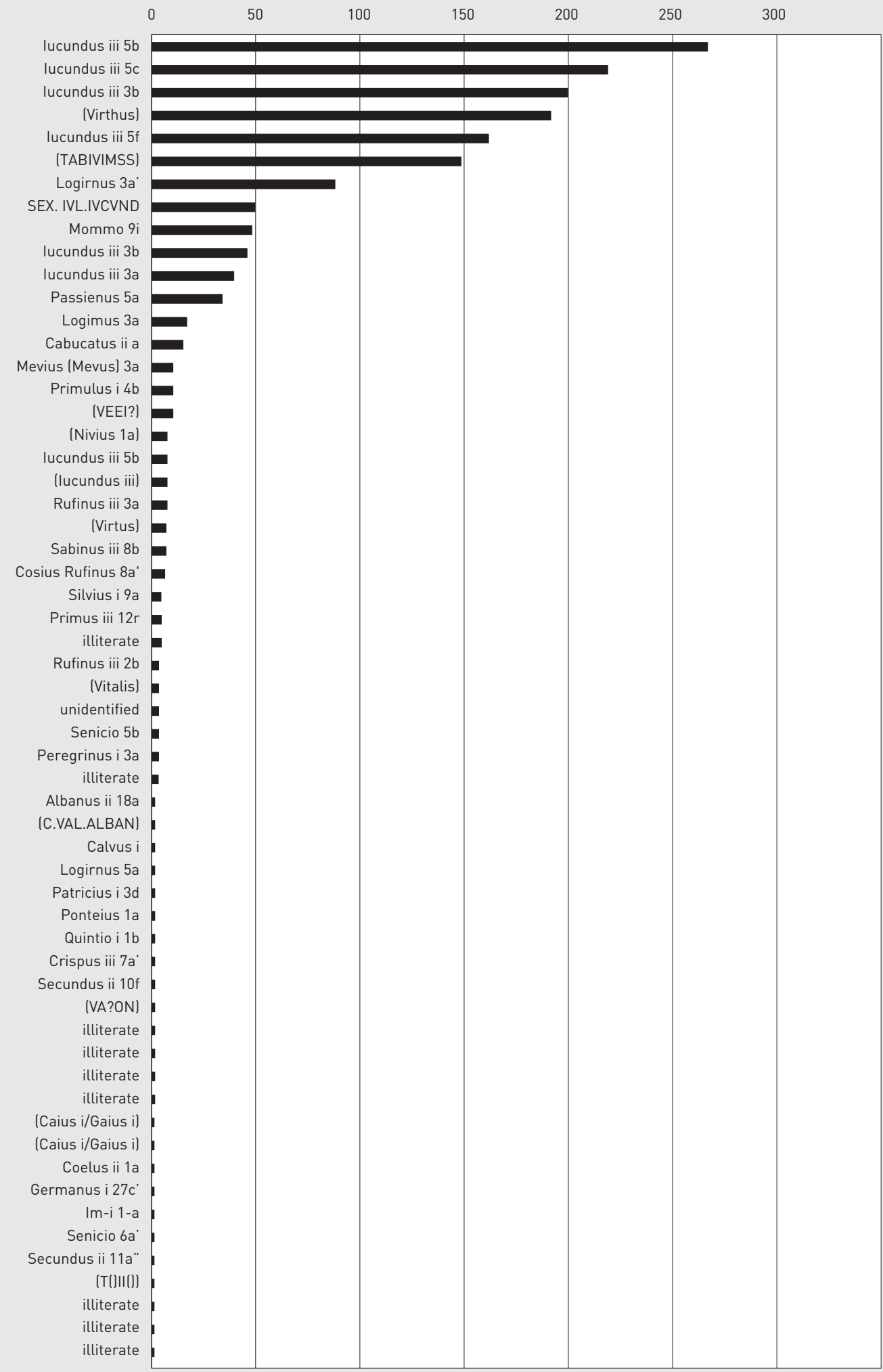

Fig. 4.4. Stamp distribution by die, Cala Culip IV (AD 69-79). Data in Appendix 1, Table 2. 
more than 100 times' ${ }^{479}$ For example with regard to form Drag. 29, 4 dies (7\%) signed 99,1 \% of all vases. ${ }^{480}$ The pattern does however not map completely onto that observed at La Nautique: whereas I identified a multimodal curve for La Nautique, reflecting multiple 'topped off' kiln loads; the Culip IV curve has a much steeper peak. This is mostly due to the extraordinary contribution of Iucundus, which is moreover mostly made up by two forms (Drag. 18 and Drag. 27). ${ }^{481}$ The order of Iucundus' share is almost consistent with that of the individual tallies on the firing lists; his name alone matches $51 \%$ of the total identified ${ }^{482}$ single stamps. Following the 'kiln load model', this could mean that it was part of a kiln load very recently brought into Narbonne, and specific parts (probably defined by forms) of which were directly shipped onto Culip IV. Upon removal of the peak caused by Iucundus, the curve is still skewed, although less pronouncedly so.

Whether the remaining, more heterogeneous part of the assemblage is due to residual or unsold pots in the warehouse (hubs model) or on board of the ship (cabotage model), is difficult to determine. Millett suggested that 'the ship acted as a floating shop, from which only small batches were dispersed at each port of call, so that in addition to the sets of newest stock from the kilns the cargo contained remainders of earlier batches which had yet to be sold'. ${ }^{483}$ Following the entire trajectory of sigillata from production site to ship, however, demonstrates that the skewed distribution of stamps may just as well have its origin in the warehouses at Narbonne. The pattern of stamps observed at Culip IV would then be no more than a logical continuation of a shift that had already occurred at Port-la-Nautique, a change in the way sigillata was defined, and in the way it was measured: no longer as indivisible kiln load, but by volume and weight. Hence the observation of a skewed distribution of number of stamps per potter cannot in itself be taken to prove either cabotage or a model of redistributive hubs.

If a single die is present on different forms, these tend to be represented in very different proportions (Appendix 1, Table 2). For instance, the die Iucundus iii $3 b^{484}$ was used on both Drag. 24/25 and Drag. 27, but counted only 7 times on the latter as against 193 examples of the former. Iucundus iii's main contribution of Drag. 27 in the Culip IV assemblage was stamped with a different die, Iucundus iii 5c. Following the hypothesis tracing the composition of this assemblage back to (part of) an incoming kiln load and several mixed-in ones, this differential proportion between different forms stamped by individual dies implies that for each kiln load each single die tended to be used for one specific form only. This correspondence between die and form varied with each firing event or kiln load, and, as is evident from a quick glance at the Names on Terra Sigillata catalogue, no universal correlation can be posited. A similar pattern can be noted for Port-la-Nautique, although less pronounced, as we are dealing here with more 'flattened out' peaks deriving from original kiln loads. For instance die Primus iii $21 \mathrm{j}^{485}$ is present on 13 examples of Drag. 24/25 but only on two examples of Drag. 27.

These observations have consequences for models of production organisation at the kiln site. It seems likely that the kiln load - as structuring principle in terms of investment and commercialization - determined the rhythm and modalities of production. For each kiln load, certain potters or officinae produced a certain number of pots of a certain form, or of multiple forms. Within the workshop the modelling was then organized on an ad-hoc basis, whereby each modelling sequence would focus on a single form and use a single die to stamp the resulting pots. Specialisation was thus a kiln load-specific concept in practice, and did not truly become tied to skilled craftsmen or to specific workshops. Even if agents of power cannot be identified, asymmetries are evident in that the principles of distribution constrained and shaped the possibilities of production.

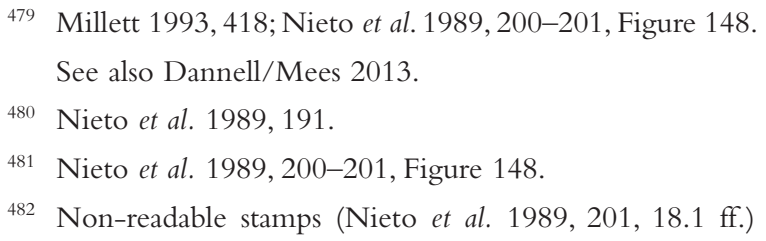

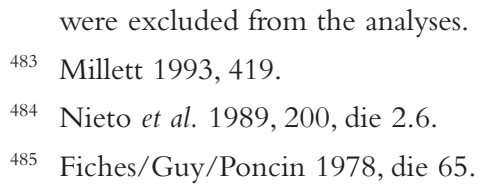




\subsection{THE COLCHESTER SHOPS: REPERCUSSIONS FOR DATING}

At Colchester (Fig. 3.2), the assemblages of two so-called potters' shops have been related to destruction by fire during the Boudiccan revolt in AD 61. ${ }^{486}$ The pottery of the First Shop has later been re-dated to AD 50-55 by Millett ${ }^{487}$, but still falls within the Neronian-Vespasian horizon and can be treated alongside that of the Second Shop for the purposes of this study. Apart from unused South Gaulish sigillata, the assemblages also contained glass, colour-coated wares, and lamps. ${ }^{48}$ Seeds found in the Second Shop indicate that provisions such as barley, spelt, lentils, figs, and coriander had been stored alongside the table wares. ${ }^{489}$ The shop assemblages form a logical continuation of the trajectory of South Gaulish sigillata; even though they are part of a northern distribution network rather than a Mediterranean one as served by Culip IV.

\section{Sigillata as a separate product}

The shops consisted of small daub and timber buildings. Based on the stratigraphy of the First Shop it seems that the sigillata pots were stored in stacks base-upwards on a lower shelf or on ground level, with the glass vessels on a higher shelf. ${ }^{490}$ Sigillata was thus again part of a multiproduct assemblage. In contrast to Culip IV, however, sigillata was now differentiated more clearly from other products, a differentiation materialized by their respective position on different shelves. This is very different to the conceptual merging of sigillata and thin-walled pottery through the parameter of volume on board Culip IV. In other words, sigillata again became a product understood in and of itself.

The segregation of sigillata is reinforced by another site at Colchester, the destruction of which has also been dated to the Boudiccan revolt. On North Hill, insula 10, a large rectangular daub structure was subdivided into smaller box-like rooms on the east side and larger rooms on the west end. The eastern compartments contained lots of pottery, some stacked on shelves, alongside wheat and bronze scales. The pottery contained a series of almost identical mortaria all stamped by Quintus Valerius Secundus, a stock of similar flagons, and a variety of amphorae. The excavator interpreted the site as a store room or 'smallscale public depot' ${ }^{491}$ A specialist appendix by Dannell lists a series of sigillata forms found in the same layers. Millett later revisited the assemblages from the original excavation and produced approximate spatial distribution maps of the different material categories, including sigillata. ${ }^{492}$ A larger than average presence of sigillata in room 1 overlapped with a concentration of mortaria. Flagons and amphorae were comparatively focused on room 5 , which lay opposite to, but not in direct connection with room 1.This pattern thus suggests that if sigillata was to any extent involved in the warehouse facilities of the building, it seems to have been characterized by an association with mortaria, and a differentiation from flagons and amphorae. Whether this association was due to supply networks or different mechanisms for storage and sale is difficult to tell. In any case, sigillata was not randomly mixed in with other goods, and operated as a meaningful unit in relation to other products. ${ }^{493}$

\section{Assemblage composition and modalities of trade $e^{494}$}

The previous case studies have shown that sigillata stamp distributions can be related to the modalities and rhythm of trade. This general method could be called the 'kiln load model', based on study of stamp distributions, where the meaningful unit of analysis is a unique combination of die and form, which can

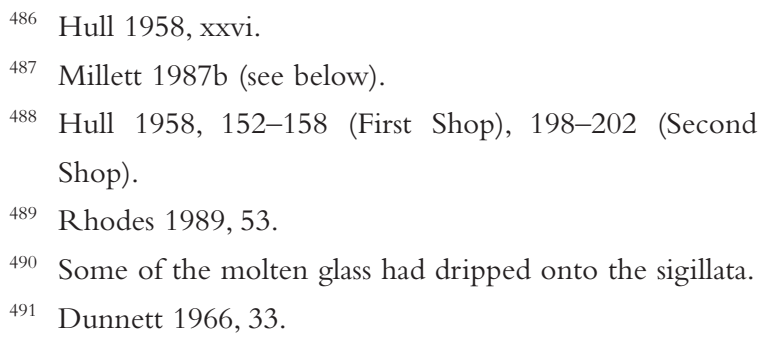

492 Millett 1983, 174.

49312 dies were recorded by Millett $(1983,305-313)$ for insula 10 , none by the same potter. Except for four examples of Drag. 27 and three of Drag. 18(R), the stamps are all on different forms too.

494 Data based on Millett 1987 b. 


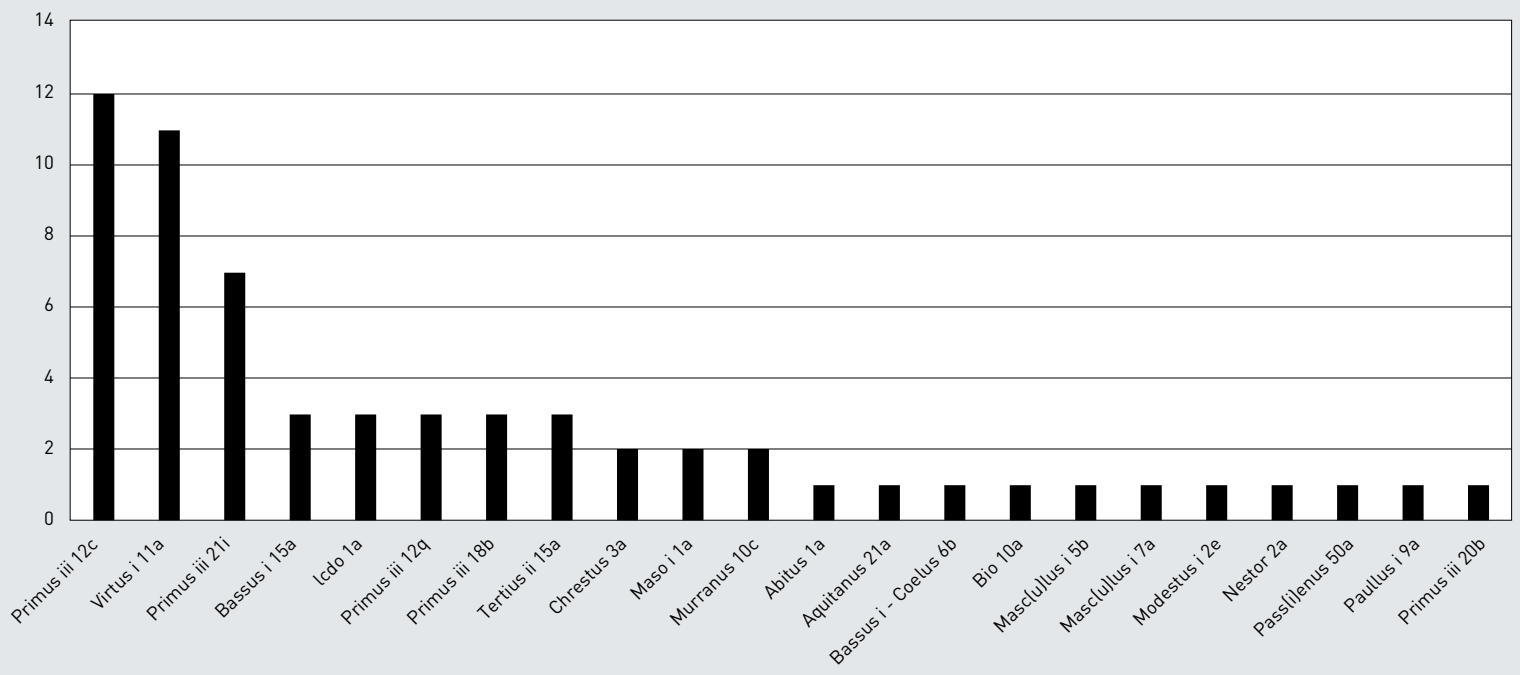

Fig. 4.5. Stamp distribution by die, Colchester First Shop (AD 50-55). Data in Appendix 1, Table 3.

be related to original (parts of) kiln loads.

There is some overlap between both Colchester assemblages and that from Port-la-Nautique: some potters' names are common to both, although no identical dies have been attested; both share the relative ordering of the most popular forms; and analogies can be drawn based on the composition and motifs of decorated vessels. ${ }^{495}$ But not only are the Colchester assemblages far less numerous than those discussed above, they also have a much lower average number of stamps per potter. ${ }^{496}$ This makes sense as Colchester is situated further down the trajectory of sigillata from producer to consumer. As the ties between potter and pot lost their ontological significance through firing, and as the kiln load was dissolved as a meaningful unit from the warehouse and initial transport onwards, the road was opened for sigillata to be mixed internally regardless of those criteria.

Comparing the shape of the stamp distributions (Figs. 4.5 and 4.6) shows a skewed pattern with a small number of dies accounting for half of the stamps in the assemblages at Colchester (in both cases about $15 \%$ of the dies add up to $50 \%$ of the total number of stamps), but this is far less pronounced than was the case for Culip IV.The pattern of Culip IV was interpreted above as an assemblage consisting of a fairly recent, homogeneous batch ((part of) a kiln load set) and a series of heterogeneous 'leftover' pots. Similarly, the heterogeneous 'tail' of the Colchester curves derives from a long process of transactions similar to the 'stock in the making' that shaped the La Nautique curve. But as the latter's multimodal shape is not equalled by the Colchester assemblages, it follows that the Shops did not receive as frequent supplies as the La Nautique warehouses: the gap between subsequent deliveries to Colchester was wide enough to allow for all original 'peaks' to be flattened out up to the same level. We cannot detect whether this happened at the Shops themselves or at a previous stage in their trajectory; but this uncertainty does not thwart the observation that the available stock at Colchester was formed by an irregular rhythm of supply, with fairly long lapses of time in between replenishments. This provides an important empirically based insight into the irregular (maybe seasonal?) availability of sigillata at the major site in Essex, which must in turn have had consequences for how sigillata was being perceived and understood.

Moreover, this has important implications for the model of distribution that can be posited between La Graufesenque and Colchester. Directional trade can be ruled out because of the heterogeneous curves

495 Fiches/Guy/Poncin 1978, 206-207.

496 Rhodes 1989, 47, Fig. 2. 


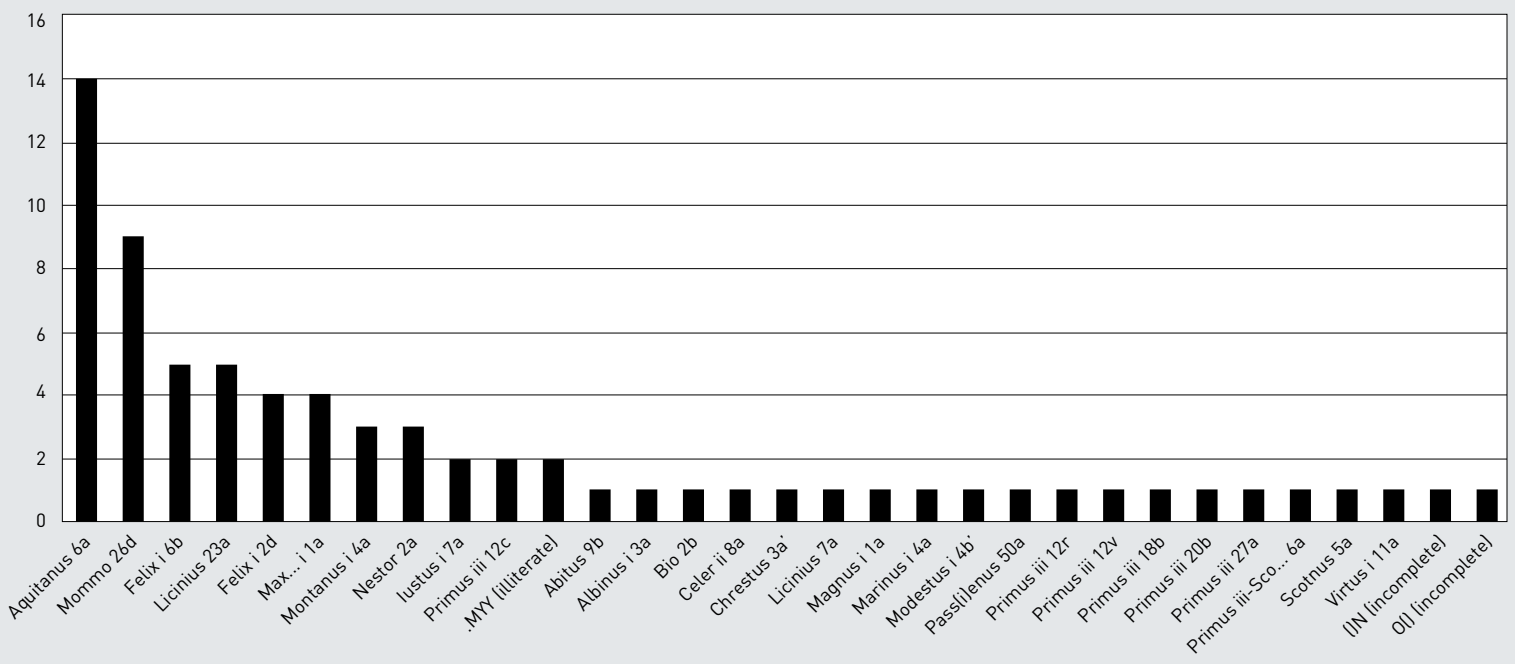

Fig. 4.6. Stamp distribution by die, Colchester Second Shop (AD 61). Data in Appendix 1, Table 4.

of stamp distributions for both assemblages. But the other extreme, highly fragmented trade, is equally unlikely: this would have resulted in mixing of the kiln load derivatives to such an extent as to make it impossible to introduce a significantly visible homogeneous peak in the stamp curve. Since such a peak is attested, it follows that a certain form/die combination was preserved well enough (i.e. in a marked quantity) throughout the different transactions to cause a wiggle in the curve. This view finds support in recent work by Dannell and Mees, which shows that 'even at great distances from the point of manufacture, the pottery recovered from [warehouse and retail outlets] represents what looks suspiciously like parcels derived from a single production source if not a single kiln firing' ${ }^{497}$

\section{Stamp distribution: chronology or kiln load rhythm?}

When Millett redated the First Shop assemblage, he started from 'the fundamental assumption on which the chronologies are based, that assemblages deposited at or near the same time, within the same distribution network, will be similar in composition. This assumption has itself rarely been tested to establish the limits within which other factors determining pottery supply, use and deposition, may obscure these underlying chronological structures, and render them unreliable for the precise dating upon which Roman archaeologists rely'. ${ }^{498}$

The kiln load model provides exactly such an as yet unexplored tangential factor that would undermine the starting assumption that contemporary assemblages, coming from the same source and going through the same distribution network, would be similar in composition. If different stamp distributions show a different curve, their respective assemblages are likely to have been formed by different modalities and rhythms of transactions and trade. So in order for Millett's chronological arguments to hold true, I have to establish that the observed differences in ceramic signature between the assemblages from both Shops did not result from different processes of supply and turnover instead of different dates of deposition.

\footnotetext{
497 Dannell/Mees 2013, 176.

498 Millett 1987b, 93. See also Millett 1987a.
} 


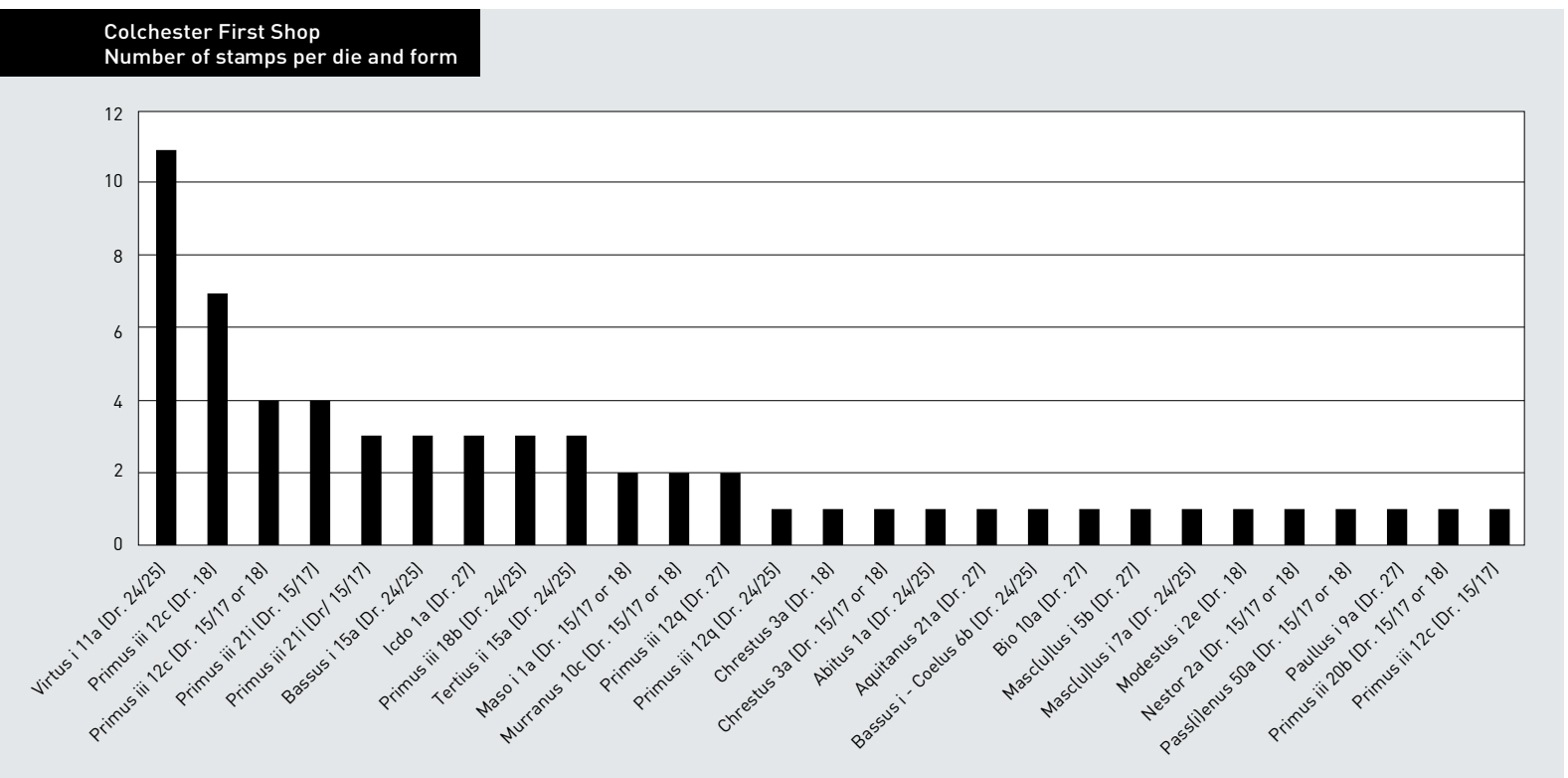

Fig. 4.7. Stamp distribution by die and form, Colchester First shop. Data in Appendix 1, Table 3.

The previous section has discussed the general comparability of the curves for both Colchester Shops, and their similarity to the peaked pattern of Culip IV. The similarity between the First and Second Shops becomes even clearer when individual dies are charted by form ${ }^{499}$ (compare Figs. 4.6 and 4.7), as the combination of die and form is what counts as derivative of an original kiln load. Another measure of comparison is the 'peak' of the stamp distribution: the largest number of stamps with a single die/ form combination divided by the total number of recorded stamps. The resultant values are 0,15 for the First Shop (11/62) and 0,19 for the Second (14/73; Appendix 1, Tables 3-4). It follows that neither of the shops was marked out by a notably more recent delivery or by a disproportionately homogeneous replenishment.

The kiln load model thus provides an important new anchor for chronological arguments, and touches on the very fundamentals of pottery dating. Verifying the modalities of trade by comparing stamp curves introduces a new, necessary 'check' on the comparability of different assemblages. Once this comparability is established - as with the Colchester Shops - other well-established parameters can date the assemblages: Millett for instance used aggregate dates of forms, decorative elements and stamps. But if analysis of the stamp curves would have pointed to a difference in modalities and rhythm of trade - as for example with La Nautique and Culip IV - an archaic ceramic signature for one of the assemblages could well be due to a lack of recent supplies instead of a different date of deposition.

\section{Form distribution: chronology or kiln load rhythm?}

What about the form distribution of the assemblages under study (Fig. 4.8)? Note that in order to be able to take La Nautique into consideration, the form distributions are plotted for stamped examples only. Firstly, the consistency between the relative percentages of the respective (stamped) forms for La Nautique on the one hand and the combined Colchester shops on the other hand demonstrates that whatever the trade route and destination (i.e. Mediterranean or northbound), the proportions of different forms traded was the same, and ran parallel to what was being produced. Similarly, the ratio of cups (Drag. 24/25 and 27) to plates (Drag. 15/17 and 18) is almost identical for the Colchester assemblages and La Nautique.

499 This does not affect the Second Shop, where each die is

represented on a single form only. 


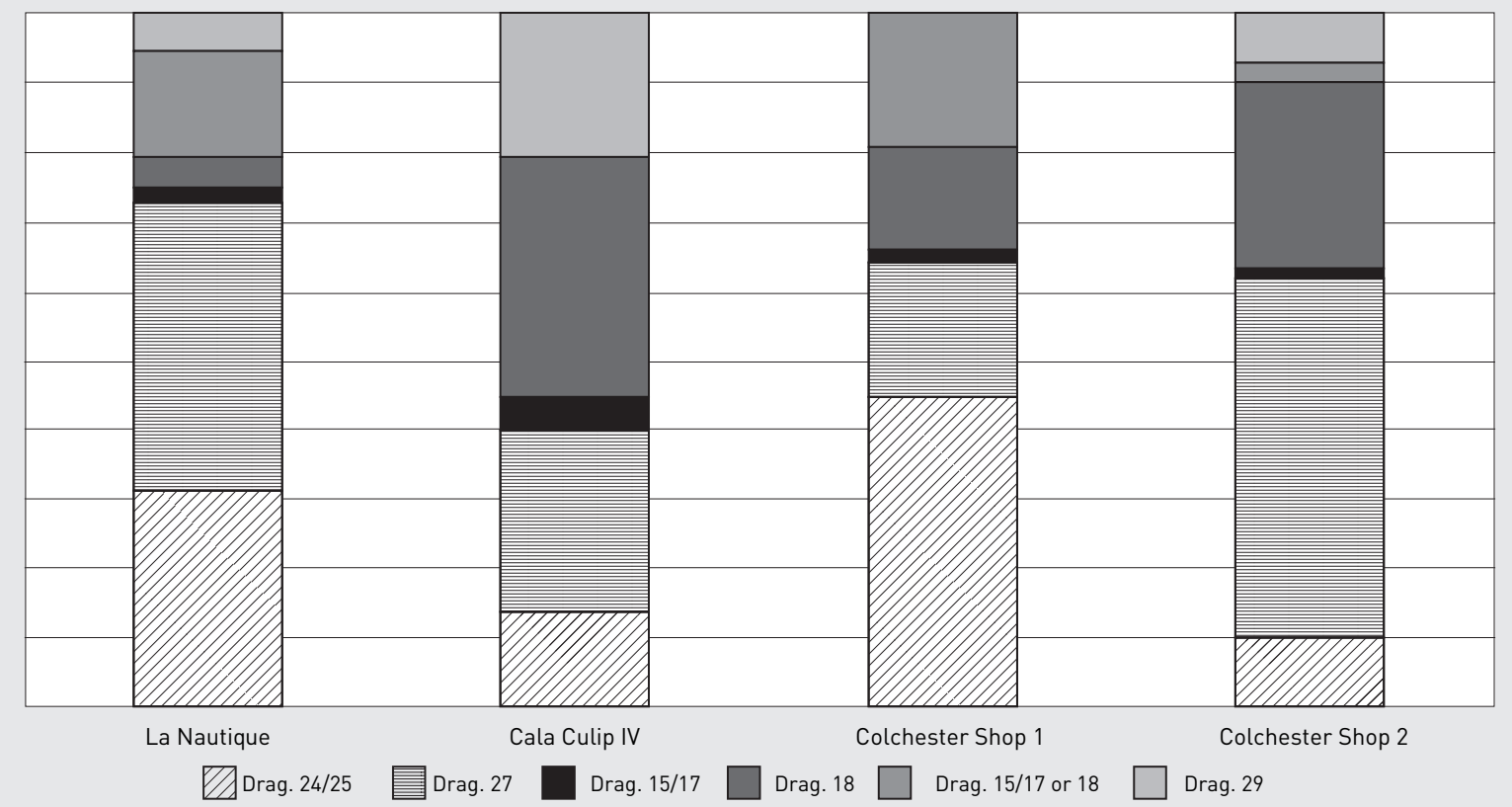

Fig. 4.8. Distribution of forms across assemblages. Data in Appendix 1.

Secondly, the distributions by form are very much shaped by the homogeneous parts, and hence by the random character of what was contained in the kiln load derivative that happened to be brought in. This could account in part for the 'abnormally' (as compared to La Nautique and Colchester) high proportion of Drag. 18 plate $^{500}$ in the Culip IV assemblage. Surely part of the answer must be to do with chronology: Drag. 18 was the newer replacement of Drag. 15/17 at La Graufesenque. ${ }^{501}$ But returning to the original spreadsheet for the assemblage (Appendix 1, Table 2), it is clear that the abnormally high representation of Drag. 18 is to be traced back to the abnormally (with regard to the internal distribution within the assemblage) high peak of two dies by a distinct potter, Iucundus iii. If, as hypothesized above, these peaks were caused by 'fresh' input of kiln load produce, and would be flattened out through further trade, then we can conclude that variation in the specific form distributions between assemblages from the same chronological horizon (and derived from a single production centre), could just as well be due to the contingency of the rhythm of production and movement of pots rather than a specific 'catering for taste'.

This could be a complementary cause for variation, in addition to the chronological factor, to account for divergences of form distributions observed in assemblages belonging to the same chronological horizon. But this comparison of form distributions should follow the establishment of the modalities of supply and assemblage composition. Again, the similarity between those modalities for the Colchester Shops allows meaningful comparison of their form ratio's, where in this case the dominance of the newer Drag. 27 and Drag. 18 (as compared to Drag. 24/25 and Drag. 15/17) ${ }^{502}$ suggests a more recent date for the Second Shop assemblage.

500 But note the large group of 'Drag. $15 / 17$ or 18 ' for La Nautique and Colchester.
501 Willis 2005, 5.3.2.2.

502 Willis 2005, 5.3 . 


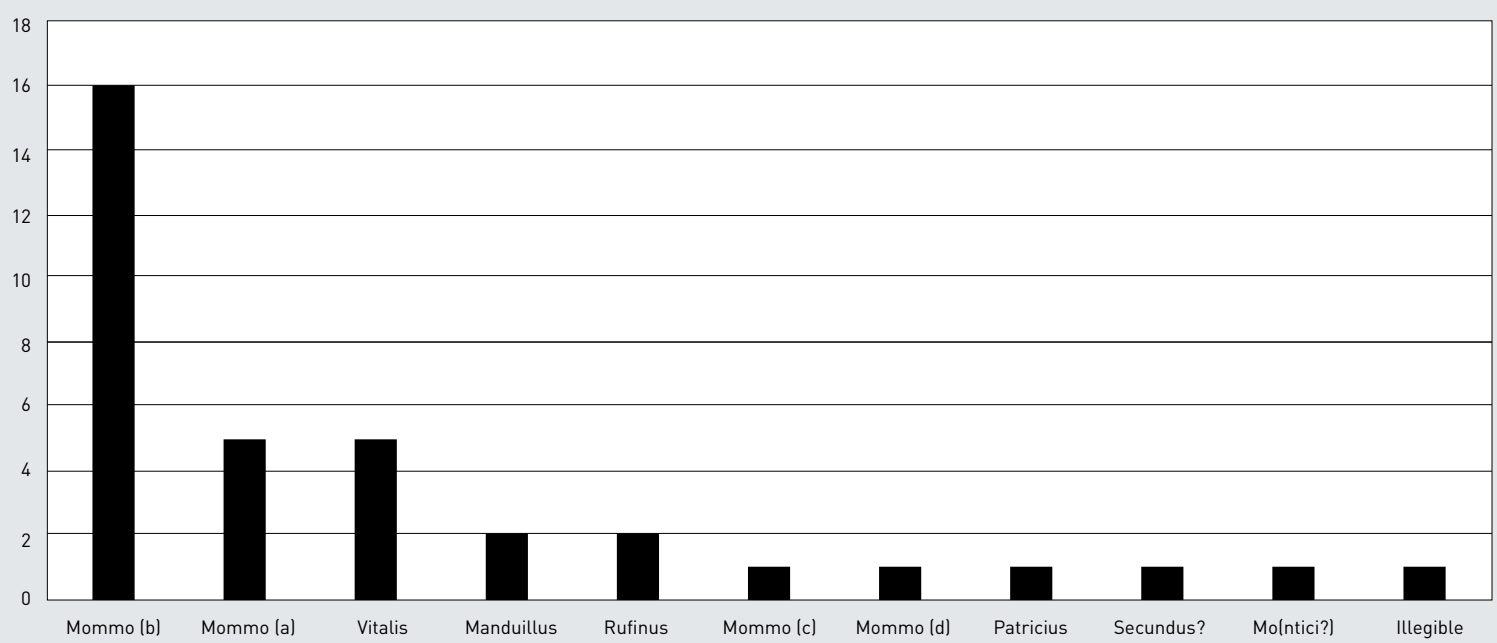

Fig. 4.9. Stamp distribution by die, Pompeii crate (AD 79).

\section{$4 \cdot 3 \cdot 5$ THE POMPEII CRATE: NORM OR ANOMALY?}

During the eruption of the Vesuvius in AD 79, a wooden crate was buried in Pompeii (Fig. 3.2). It was discovered in October 1881, in the tablinum of house 9, insula 5, regio VIII. ${ }^{503}$ The excavation notes describe a deposit of unused coral red and black slipped cups and lamps, ordered in a wooden crate. ${ }^{504}$ More specifically, 90 South Gaulish decorated sigillata bowls had been arranged in a wooden crate - the charred remains of which survived - along with 37 ceramic lamps originating from northern Italy. ${ }^{505}$ The sigillata consisted only of decorated bowls, 36 of form Drag. 29 and 54 examples of Drag. 37. ${ }^{506}$ All were completely preserved and unused, some bases still covered in the sand particles on which they had been dried. ${ }^{507}$ Alongside this crate two more boxes were found containing 'red earth', either crushed brick or a pigment for wall covers. ${ }^{508}$

When Atkinson first published the sigillata bowls, he interpreted them as 'a consignment lately received in Pompeii from a wholesale dealer in such wares' ${ }^{509}$ Moreover, he inserted lamps and sigillata in a single flow of trade: [ $[\mathrm{t}]$ he presence of lamps of Fortis and Comunis, whose factories are usually assigned to northern Italy, indicates that the bowls did not reach Pompeii direct from their place of manufacture in southern Gaul'. ${ }^{510}$ Hence both the crate and its contents have entered the literature and scholarly imagination as a pristine remnant of and a transparent window on trade flows between South Gaul and Pompeii, via northern Italy: a batch of brand-new sigillata straight from the production site being complemented by a set of lamps along the way. This assumption is based on the fact that both lamps and bowls were unused, and on their 'packed up' state in a wooden crate: as if they had literally just arrived on the spot. But is this in accordance with the modalities of trade deduced from the 'kiln load model'? Only

503 Gassner 1986, 201, nrs VIII 5, 10 and VIII 5, 11.12 for discussion of the house's possible commercial role as taberna, based on architectural analysis. For other discoveries in the same house, see Atti della Reale Accademia dei Lincei 1880-81. Serie 3. Memorie della classe di Scienze morali, storiche e filologiche 7, 463, 539; and 9, 433--435.

504 Atti Lincei 9, 412 ff. Black colour probably due to scorching of the red slip.
505 Atkinson 1914, 26, 28.

506 Atkinson 1914, who studied the assemblage in Naples. Data on forms and stamps were not included in the excavation notes.

507 Atkinson 1914, 28.

508 Atti Lincei 9, 435.

509 Atkinson 1914, 28.

510 Atkinson 1914, 28. 
the Drag. 29 bowls had been stamped internally. ${ }^{511}$ Individual dies can only be derived from Atkinson's transcriptions, but the overall distribution of internal stamps is as follows ${ }^{512}$ :

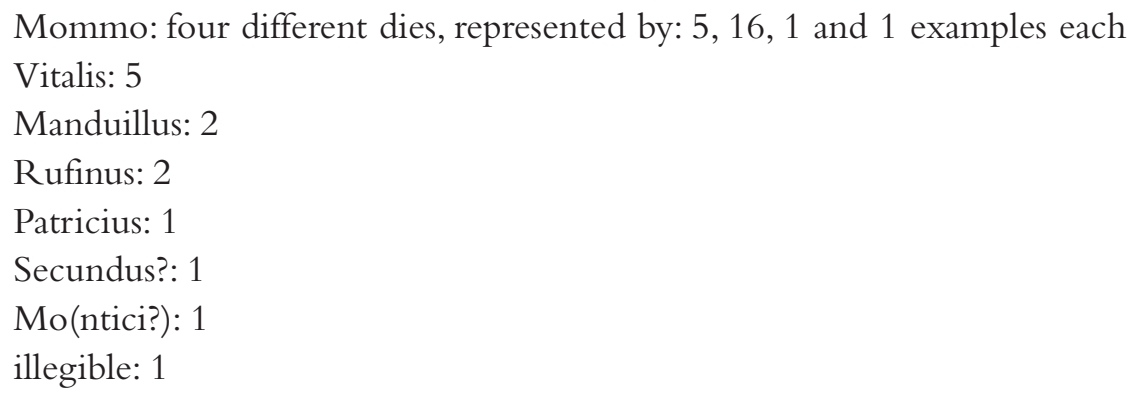

It is at once clear that this distribution is highly skewed (Fig. 4.9), with a single die (Mommo (b)) accounting for $44 \%(16 / 36)$ of the entire consignment of Drag. 29. So again there is a homogeneous peak of many pots by a single potter against a heterogeneous background of few pots by many potters. This is different from the pattern expected if the sigillata in the Pompeii case would have travelled as a set all the way from La Graufesenque: in that case, the desired quantity of Drag. 29 bowls would have been directly extracted from a single kiln load, which would have resulted in a more even stamp distribution. Instead the pattern is similar to the curves of both Cala Culip IV and the Colchester Shops and indicative of a process of stock-in-the-making with a recent replenishment. It can thus be hypothesized that the vessels stamped by die Mommo (b) were part of a different initial kiln load than the other potters' vessels. Moreover, the marked difference between the number of Mommo (b) stamps and that of the 'background' potters suggests that there was a substantial gap between the former's addition to the latter. If not, one would expect more 'mixing in' of Mommo (b) stamps. These observations hold true regardless of where the bowls were packed in the crate, although it is likely that this happened in an intervening warehouse-type setting, similar to the process reconstructed for Colchester. But in a similar vein as the Colchester assemblage, this sigillata assemblage's trajectory cannot have been highly fragmented: if so, the Mommo (b) peak could be expected to have flattened out, which is not the case.

So does this crate - and the two joining ones containing the red earth - represent a different type of economic action, where a specific, clearly defined demand crystallized in the (semi-)directional supply of three idiosyncratic crates to a specific customer? The stamp distribution cautions against this hypothesis. Instead, the curve is in perfect accordance with other 'normal' points of turnover like Culip IV and the Colchester Shops.

But contrary to these previous assemblages, it is not clear that the Pompeii crate functioned in the context of a 'shop'. More contextual detail is needed. Unfortunately the relevant excavation notes of the 1880 s are not very elaborate, and the material belonging to this context and house has not been consistently kept apart. ${ }^{513}$ Various disparate finds have been recorded for the other rooms of the house: small amphorae, glass vessels, serving ware in different materials, some coins of low denomination. The sigillata bowls and lamps are the only consistent set of material discovered, and the three crates seem to be the only example of deliberately packed-up goods. One exception to the dominance of storage and serving vessels ${ }^{514}$ are a set of tools found in the first room adjoining the peristilium on the right hand side: a hoe

511 None of the Drag. 37 examples were stamped internally, and only three yielded an intra-decorative stamp, respectively by Memor, Mommo and Mo(destus?) (Atkinson 1914, 30).

512 These data are drawn from Atkinson 1914, 29 and could not be verified against the Names on Terra Sigillata cata- logue as no reproductions of the dies have been published.

513 Atti Lincei 7, 463, 539; Atti Lincei 9, 433-435.

514 The absence of cooking wares could be due to this category not having been recorded in the early excavations (a single ceramic lid is mentioned). 
or pickaxe (length 29,5 cm), a hatchet with a double blade (length 22,0 cm), and some fragments of a saw, all in iron. ${ }^{515}$ Further objects in that room were a ceramic bowl containing lime, a bruised bronze bowl with unsoldered handles, a bronze flexible peg, seven amphorae, and two medium value coins.

It is known that Pompeii had suffered a series of earthquakes between AD 62 and the eruption of the Vesuvius in $\mathrm{AD} 79$, and that some of the resulting damage had not yet been repaired when an ash layer finally covered the city. ${ }^{516}$ The tools, the peg and the ceramic bowl containing lime could attest to such repair work in the house under study. ${ }^{517}$ If the lime suggests re-plastering, then it is not inconceivable that the red earth found in the two crates in the tablinum served as pigment or substance in this process. Where does this leave the crate with sigillata and lamps? As the tools and red earth indicate repair works following an earthquake, the decorated sigillata bowls and lamps might have been packed-up for protection during these refurbishments, possibly as 'new' goods that still had to be sold on, or were worth shielding off from the vagaries of dust and paint.

To consolidate this argument further, other examples of packed-up sets of material during repair works at Pompeii can be mentioned. Varone published a picture of a similar ceramic bowl containing lime from a bakery (house IX.12.6) whose implements showed signs of seismic damage too. Nappo mentions the yellow pozzolana stored and used in house II.8.6 for the painting of new wall decorations, replacing ones in an older style that were damaged by an earthquake. ${ }^{518}$ Berry in turn has investigated in detail the evidence for houses I.9.11 and I.9.12. Like the house under study here, these show evidence of planned repair works: "building material in the atrium in the form of a pile of pozzolana, amphorae filled with pozzolana and cocciopesto, a pile of blue pigment, and two dressed Sarno stone blocks'. ${ }^{519}$ In contrast to the 'sigillata house', however, no tools or equipment were found, and the building works largely seem to have been abandoned by AD 79. Also in contrast to the 'sigillata house', few or any domestic artefacts have been reported for houses I.9.11 and I.9.12; none of them cooking implements, and all of them in a context of storage in the portico rather than in current use. Despite the lack of a crate or other storage facilities, this recalls our hypothesis of stowed away sigillata and lamps in house 9. The excavation report of the latter however did make mention of several domestic objects scattered around the other spaces whereas the spaces of houses I.9.11 and I.9.12 had been overtaken by commercially oriented activities, with the presence of two large sets of amphorae and a mule pointing towards transport and turnover of goods. Another example is house I.8.14, where a large range of artefacts was distributed over several spaces. In the fauces leading onto the street a remarkable concentration of gold and silver objects was found in association with a wooden chest. ${ }^{520}$ Given the location, this is more likely to have been related to packing-up for a flight rather than storage and protection during repair works, but nevertheless here too we see an ad-hoc selection of valuable items packed-up in a closed container. Finally, in house I.9.12 - which showed evidence of restoration works during its habitation - a chest was found containing various metal and glass objects, coins, sigillata, and ceramic lamps. ${ }^{521}$ These and many other examples prove the impact of the different earthquakes preceding the AD 79 eruption on Pompeian domestic life, as well as the various contingent responses resulting in the rebuilding, restructuring, or re-destination of spaces and activities. ${ }^{522}$

If this hypothesis is correct, this does not thwart the observations on the modalities of trade of the sigillata assemblage as such. But it does recontextualize the specificities of packing up, and the resultant associations. Hence any parameter by which the assemblage as a whole was organized speaks first and

515 Atti dei Lincei 9, 414.

516 See Archäologie und Seismologie 1995 for archaeological indicators, esp. De Simone 1995; Nappo 1995; Varone 1995; Berry 1997a, 103-104.

517 Thanks to Martin Millett for first suggesting this idea.

518 Nappo 1995, 47.
519 Berry 1997a, 119.

520 Berry 1997b, 190, 193.

521 Berry 2007.

522 Berry 1997b, 185 for a cautionary note on narratives of disruption during the last couple of years of Pompeii's existence. 
foremost to choices made within the contingent historical matrix of house VIII.5.9 and Pompeii at a time of functional re-destinations and restorations. The most striking feature of the set of sigillata bowls is the absence of plain wares, which otherwise tend to be the majority of what was produced at and distributed from La Graufesenque. ${ }^{523}$ The corollary of this with regard to the understanding of sigillata is that the meaningful unit was no longer even sigillata in itself - as we observed for the Colchester shops - but a much more specific category of 'decorated red slipped bowls'. But it is not certain that no plain sigillata had been delivered alongside the decorated bowls; only that these were not packed-up for protection during repair works.

Similarly, the association of decorated bowls with lamps can have resulted from ad hoc requirements of packing-up/protection rather than being the pristine remnant of a single trade flow as Atkinson assumed. Berry cautions that for the many examples of storage-related contexts in Pompeii, '[t]here often appears to be no system or pattern in the artefact types; thus, for example, glass vessels may be stored with both bronze vessels and ceramic commonwares' ${ }^{524}$ Instead, the association enacted through packing up could have been due to the items' destination for further petty trade. Non-canonical activities such as storage or petty trade in a tablinum would tie in with the functional re-designations of spaces and the mosaic of previously delineated activities during the last decades of Pompeii's existence. This would also help to account for the relatively large number of pots: 90 bowls can hardly have been destined for use on a day-to-day basis, even in an extended household.

If the general hypothesis developed above is correct, then the Pompeii crate no longer offers a pristine window on a specialized trade flow of decorated sigillata and lamps. A series of implicit assumptions need to be questioned in the wake of this reinterpretation. Maybe production and distribution were not as adjusted to demand as scholars are inclined to think on the basis of modern consumer markets and the supply/demand balance of the neoclassical market mechanism. ${ }^{525}$ Instead, the Pompeii crate sheds light on the cross-sectioning of activities in a Pompeii that was revisiting its make-up.

\subsubsection{REDEFINITION AND ECONOMIC NARRATIVES}

If sigillata is no longer retrospectively assumed to have been the same thing always and everywhere, then we can start examining how its definition changed. This section continued the trajectory of sigillata pots fired at $\mathrm{La}$ Graufesenque in the 1st century AD through a series of points of turnover. Each of these settings brought different parameters to bear on sigillata. Requirements of space foregrounded volume on board Cala Culip; at Colchester sigillata pots had to be visibly stacked on shelves in multi-product retail setting; and at Pompeii sigillata vessels found themselves subject to the vagaries of earthquakes.

Attention to these redefinitions leads to new questions, with the potential to make important additions to sigillata's use as history-teller, in particular as evidence for economic processes. For example, it inspired analysis to reconsider the well-established case of the Pompeii crate. The special selection of decorated bowls and lamps can no longer be read as a pristine, key example of trading mechanisms, but has been situated in local socio-historical dynamics at Pompeii. Consequently its status as template for (sigillata) trade networks should be revised. Moreover, the example of the Pompeii crate shows how many claims and assumptions that circulate widely in scholarship are based on contentious or unwarranted tropes that have acquired the status of historical 'givens'. In retrospect, the Pompeii's crate status as a 'consumer-oriented' selection is largely due to the decontextualized publication by Atkinson and the

523 Cf. assemblages discussed above; Willis 2005 for Britain.

524 Berry 1997b, 194.

525 Even in those modern 'consumer markets' it is questionable to what extent they are consumer-driven. Rather, producers use various mechanisms (e.g. marketing) to shape and create consumers and their demands (Slater 2002a, 2002b; discussions Cambridge Social Ontology Group, Economics). 
obscurity of the excavation report. These factors both contributed to and resulted from the creation of sigillata as a bounded, well-defined category, to be studied separately.

Further ramifications concern the organisation of trade in Roman times. The kiln load model enables approximate analysis of the rhythm of supply, and hence of the regularity of trading flows. The die curves for Colchester for example rule out both extremes of directional trade and highly fragmented trade, based on the rhythm and extent of 'mixing in' of older and newer consignments (kiln load derivatives). But comparison with the process of 'stock in the making' postulated for Port-la-Nautique in turn showed that the influx of new consignments would have been much more irregular at Colchester. This observation helps to come to terms with how sigillata was perceived, understood and defined at the consumer's end.

Furthermore, the kiln load model indirectly provides a handle on the organisation of sigillata production. For example, detailed analysis of the stamp distributions per assemblage showed that specific combinations of die and form could be traced back to single kiln loads, but that these combinations did not recur throughout different kiln loads (the derivatives of which were mixed in a single assemblage). On this basis specialisation of production by form can be ruled out ${ }^{526}$ : the allocation of tasks seems to have been an ad-hoc procedure. Similarly, the principles of the kiln load model revealed a situated but real asymmetry: paradoxically, the kiln load was the format for the rhythm and modalities of production, as the structuring principle of investment and 'marketing'. This shows how the investment axis influenced enactments of sigillata in other fields of practice. Hence we can access power relations and asymmetries in practice rather than through abstract assumptions - even though the specific agents of power cannot be identified.

Similarly, interpretation of the misfired pots on board Culip IV was challenged. Within the confines of a neoclassical economic mould Nieto is at pains to 'rationalize' this apparently 'irrational' choice: demand for sigillata would have exceeded supply to such an extent that even 'waste' products could be sold, although at a lower price. This argument not only hinges on assumptions regarding the structure and performance of the economy, but also presupposes a universal parameter for evaluating sigillata - a sliding scale of values that are mapped onto (or represented by) sigillata. Attention to the shifting settings and the attendant parameters has shown that the organizing principle of volume on board Culip IV simply did not differentiate in practice between what had been 'good' and 'misfired' sigillata pots during production.

Finally, traditional concerns such as the issue of 'risk' can now be reformulated too. From the different parameters of the consecutive settings, it follows that there was no universal standard against which sigillata's performance could be evaluated. This does not only mean that a factor such as 'risk' cannot always be calculated based on the same parameters, but that what risk is varies too. During firing, risk called upon the unaccountable (via raven/cross, casidanos/flamen) in an attempt to stabilize uncertainty. From La Graufesenque to Narbonne, risk resided solely in sigillata, and was clearly defined as an either/or outcome: either the kiln load reached Narbonne or it did not. Directionality was key in this enactment, even though it is not a factor accounted for in neoclassical risk calculations. On board Cala Culip IV, sigillata was transformed from a high-risk commodity to a low-risk or potentially risk-reducing lightweight 'extra'. As a consequence, caution is needed when characterizing the Roman economy as for instance a 'zero risk' economy ${ }^{527}$, with structural constraints ${ }^{52}$ acting as a brake on risk-taking activity. Although such claims do attempt to model the Roman economy as a variable set of relations, their unquestioning acceptance of rigid parameters like 'risk' corrodes any veneer of actual contingency.

In sum, the sequence of assemblages studied in this section does not provide a new, encompassing reconstruction of the marketing and transport of sigillata. Instead, the case studies illustrate how to put

526 Similar conclusions have been arrived at by other means,

e.g. Genin 2007; Mees 2013, 96.
527 Poblome 2013, 92.

528 E.g. Horden/Purcell 2000. 
to work a non-retrospective model of material culture. As such they give a flavour of the kinds of social transactions and negotiations that such a different model of material culture can open up, negotiations that have hitherto been taken for granted or filtered out in studies of sigillata distribution. All of the listed contributions to sigillata's role as historical evidence (history-teller) were only made possible by abandoning the standard starting assumption that sigillata always was a homogeneous, stable, standardized category, with pots that can be represented as dots on a map.

\section{$4 \cdot 4$ A CATEGORY'S TRA JECTORY OF EXCHANGE}

This chapter has shown how abandoning a retrospective approach to sigillata - and, by extension, material culture - can lead to real advances in existing debates based on sigillata: interpreting the firing lists, or getting to grips with trade mechanisms. This book's overall approach can thus help refine sigillata's role as history-teller. But this chapter has also shown sigillata at work as history-maker.

Each point of turnover in the sequence of sigillata trade discussed in this chapter came with its own requirements: craftsmanship, volume, shape, etc. This opened up scope to examine the different parameters to which sigillata had to conform in each of these stages. But despite the different settings and their requirements, sigillata flowed through these points of turnover as a singular commodity. How was this possible?

The discussion of firing lists concluded that sigillata's definition as a category in production (previous chapter) provided something of a template (binary boundaries, package of traits), which the firing lists further articulated by pinning down reference points for its traits. As a category, sigillata enabled comparison and competition. The firing lists helped the production sequence of sigillata reach closure, by positing 'good' sigillata as an end point of production. As a consequence, they cut the links between potter and pot. When sigillata pots left the production site at La Graufesenque (or, by extension, at Lezoux), they could enter into commodity exchange. And this was facilitated precisely by their flexibility to foreground certain traits from their identifying package in response to the requirements of certain settings. Sigillata's prior definition as a category assured that its different instantiations, emphasizing a selected number of traits from its package, did not lead to incongruity: a recognizable sigillata-as-a-category template assured continuity despite changes in parameters.

The category 'computer' again provides a helpful parallel. The previous chapter discussed how it is defined by a limited package of traits. As this package crystallizes, different traits can be foregrounded in adjustment to the requirements of a specific setting. For gaming fans, the size of the memory card will be decisive, but this does not mean that the other traits of the package disappear. Indeed, a gamer may well be primarily interested in the memory capacity of the device, but she will still have to make a choice about other traits such as keyboard, screen, or word processing software. Conversely, a large screen size may be paramount for a library terminal, but the computer will still come with keyboard, memory card, etc.

The continuity across the different steps in sigillata trade - the continuity of commodity trade - was thus an achievement facilitated by its category-ness and the resulting material agency. Sigillata itself set certain conditions for its exchange, as a history-maker shaping its own historical trajectory.

The resulting pattern of sigillata pots spreading widely can now be taken for what it is: a result, not a starting point. Harris claimed that '[i]t is (...) impossible to see how the potters of La Graufesenque can have been producing for anything other than a market system ${ }^{529}$. But such a market-system, if existing,

529 Harris 1993, 16. But counterarguments can also be made.

E.g. why is La Graufesenque located in a steep-sloped

valley if dictated by modern market principles? 
was itself a historical outcome, which was actively given shape and facilitated by the products circulating within it. The 'global' reach of sigillata cannot fully be explained by its assumed links with Roman culture, or by its expected higher value. Instead, it was sigillata's specific definition as a category that allowed it to enter into commodity exchange and to travel smoothly through different points of turnover. As a history-maker, sigillata created the frame for the co-emergence of 'rational' economic actors on the one hand and 'trade-able', calculable commodities on the other. 